\title{
Assessment of the potential role of atmospheric particulate pollution and airborne transmission in intensifying the first wave pandemic impact of SARS-CoV-2/COVID-19 in Northern Italy
}

\author{
Paolo Di Girolamo ${ }^{1}$
}

Received: 20 August 2020 / Accepted: 24 November 2020/Published online: 21 December 2020

(C) The Author(s) 2020, corrected publication 2021

\begin{abstract}
The severe acute respiratory syndrome coronavirus 2 (SARS-CoV-2), which exploded in Wuhan (Hebei Region, China) in late 2019, has later spread around the world, causing pandemic effects on humans. During the first wave of the pandemic, Italy, and especially its Northern regions around the Po Valley, faced severe consequences in terms of infected individuals and casualties (more than 31,000 deaths and 255,000 infected people by midMay 2020). While the spread and effective impact of the virus is primarily related to the lifestyles and social habits of the different human communities, environmental and meteorological factors also play a role. Among these, particulate pollution may directly impact the human respiratory system or act as virus carrier, thus behaving as potential amplifying factor in the pandemic spread of SARS-CoV-2. Enhanced levels of $\mathrm{PM}_{2.5}$ and $\mathrm{PM}_{10}$ particles in Northern Italy were observed over the 2-month period preceding the virus pandemic spread. Threshold levels for $\mathrm{PM}_{10}\left(<50 \mu \mathrm{g} / \mathrm{m}^{3}\right)$ were exceeded on 20 35 days over the period January-February 2020 in many areas in the Po Valley, where major effects in terms of infections and casualties occurred, with levels in excess of $80 \mu \mathrm{g} / \mathrm{m}^{3}$ occasionally observed in the $1-3$ weeks preceding the contagious activation around February 25, 2020. Threshold values for $\mathrm{PM}_{2.5}$ indicated in WHO air quality guidelines $\left(<25 \mu \mathrm{g} / \mathrm{m}^{3}\right)$ were exceeded on more than 40 days over the period JanuaryFebruary 2020 in large portions of the Po Valley, with levels up to $70 \mu \mathrm{g} / \mathrm{m}^{3}$ observed in the weeks preceding the contagious activation. In this paper, $\mathrm{PM}_{10}$ particle measurements are compared with epidemiologic parameters' data. Specifically, a statistical analysis is carried out to correlate the infection rate, or incidence of the pathology, the mortality rate, and the case fatality rate with PM concentrations. The study considers epidemiologic data for all 110 Italian provinces, as reported by the Italian Statistics Institute, over the period 20 February-31 March 2020. Corresponding $\mathrm{PM}_{10}$ concentrations covering the period
\end{abstract}

Paolo Di Girolamo

paolo.digirolamo@unibas.it

1 Scuola di Ingegneria, Università degli Studi della Basilicata, Viale dell'Ateneo Lucano, 10, 85100 Potenza, Italy 
15-26 February 2020 were collected from the network of air quality monitoring stations run by different regional and provincial environment agencies. The case fatality rate is found to be highly correlated to the average $\mathrm{PM}_{10}$ concentration, with a correlation coefficient of 0.89 and a slope of the regression line of $(6.7 \pm 0.3) \times 10^{-3} \mathrm{~m}^{3} / \mu \mathrm{g}$, which implies a doubling (from 3 to $6 \%$ ) of the mortality rate of infected patients for an average $\mathrm{PM}_{10}$ concentration increase from 22 to $27 \mu \mathrm{g} / \mathrm{m}^{3}$. Infection and mortality rates are also found to be correlated with $\mathrm{PM}_{10}$ concentrations, with correlation coefficients being 0.82 and 0.80 , respectively, and the slopes of the regression lines indicating a doubling (from 1 to $2 \%$ ) of the infection rate and a tripling (from 0.1 to $0.3 \%$ ) of the mortality rate for an average $\mathrm{PM}_{10}$ concentration increase from 25 to $29 \mu \mathrm{g} / \mathrm{m}^{3}$. Considerations on the exhaled particles' sizes, their concentrations and residence times, the transported viral dose and the minimum infective dose, in combination with $\mathrm{PM}_{2.5}$ and $\mathrm{PM}_{10}$ pollution measurements and an analytical microphysical model, allowed assessing the potential role of airborne transmission through virus-laden PM particles, in addition to droplet and the traditional airborne transmission, in conveying SARS-CoV-2 in the human respiratory system. In specific circumstances which can be found in indoor environments, the number of small potentially infectious particles coalescing on $\mathrm{PM}_{2.5}$ and $\mathrm{PM}_{10}$ particles is estimated to exceed the number of infectious particles needed to activate COVID-19 infection in humans.

Keywords COVID-19 $\cdot \mathrm{SARS}-\mathrm{CoV}-2 \cdot$ Environmental pollution $\cdot \mathrm{PM}_{2.5} \cdot \mathrm{PM}_{10} \cdot$ Epidemiologic parameters $\cdot$ Airborne virus transmission

\section{Introduction}

$\mathrm{PM}_{2.5}$ and $\mathrm{PM}_{10}$ are particles with an aerodynamic diameter smaller than 2.5 and $10 \mu \mathrm{m}$, respectively, which are often present in the air. These small particles can be either organic or inorganic and can be present in both solid and liquid phase. They are capable of adsorbing on their surface various substances with toxic properties such as sulfates, nitrates, metals, and volatile compounds (Park et al. 2018).

Suspended $\mathrm{PM}_{2.5}$ and $\mathrm{PM}_{10}$ particles have a significant impact on human health, the higher being their concentration, the greater being their health impact (Dockery et al. 1993; Pope et al. 1995; Brunekreef 1997; Hoek et al. 2002). More specifically, atmospheric aerosols play an important role in triggering pro-inflammation and oxidation mechanisms of the lungs. Prolonged exposure to $\mathrm{PM}_{2.5}$ and $\mathrm{PM}_{10}$ particles has been found to be linked to acute respiratory inflammation and immunological alterations ( $\mathrm{Li}$ et al. 2018; Losacco and Perillo 2018). Aerosols can represent an important vehicle for virus transmission (Sattar and Ijaz 1987; Fabian et al. 2008; Tellier 2009).

In the present paper, we report a statistical analysis correlating SARS-CoV-2/ COVID-19 epidemiologic parameters to $\mathrm{PM}_{10}$ particle concentration measurements. This is not the first attempt to correlate COVID-19 epidemiologic parameters with particulate matter pollution. In a recent paper by Setti et al. (2020a), the relationship between the $\mathrm{PM}_{10}$ daily limit value exceedances and COVID-19 infection rate was investigated for the different Italian provinces and the statistical significance of results was assessed based on an estimate of the $p$ value. The number of exceedances of $\mathrm{PM}_{10}$ daily limit value is certainly a quantitative indicator of the frequency of high 
pollution events, but it is not an effective quantitative indicator of the time persistency of pollution conditions. Additionally, Setti et al. (2020a) focused only on one epidemiologic parameter, i.e., the infection rate, but did not consider other important parameters as the mortality rate and the case fatality rate, which are of paramount importance for an effective assessment of a pandemic outbreak impact. The study by Setti et al. (2020a) considers the infection rate over a quite short time interval (24 February-13 March 2020); this interval represents a brief sub-portion of the lockdown period imposed to Italy. Furthermore, this time interval is a small sub-portion of the period characterized by the highest number of infections and deaths, thus resulting to be not particularly effective in representing the highest pandemic outbreak period of the pandemic.

In a recent paper by Borro et al. (2020), the variability of the infection rate, the mortality rate, and the case fatality rate as a function of particle concentration was estimated for $\mathrm{PM}_{2.5}$ particles only, recognizing a primary role of these smaller particles in inducing an over-expression of the angiotensin conversion enzyme 2 (ACE-2) in the human respiratory system (see papers by Gemmati et al. 2020; Devaux et al. 2020; Bunyavanich et al. 2020; Leung et al. 2020), and consequently in enhancing COVID-19 epidemiologic impact. In the present paper, we extend the analysis to $\mathrm{PM}_{10}$ particles.

Furthermore, in the study by Borro et al. (2020), particulate matter measurements from a single station for each province were considered, while in the present study, we consider measurements from all ground stations present within each province territory, which allows to account for the natural variability of the particulate loading within the single province territories, including urban, semi-urban, and rural areas. In fact, particulate concentration variability within each province territory may be large; this variability may severely affect the degree of correlation between epidemiologic parameters and atmospheric pollution and needs to be properly accounted for. For this purpose, particulate concentration variability, i.e., its standard deviation, within each province territory is used as a weighting factor in the present statistical analysis correlating epidemiologic factors with $\mathrm{PM}_{10}$ concentrations.

The paper outline is the following. Section 2 shortly describes compositional, size and microphysical properties of $\mathrm{PM}_{2.5}$ and $\mathrm{PM}_{10}$ particles. Section 3 illustrates the possible interaction mechanisms of aerosol particles with the human respiratory system. Section 4 provides an assessment of the potential role of airborne transmission through virus-laden PM particles. Section 5 illustrates the different datasets and sensors used in the study. Section 6 illustrates the evolution of $\mathrm{PM}_{2.5}$ and $\mathrm{PM}_{10}$ concentrations shortly before the pandemic outbreak and results in terms of correlations between epidemiologic parameters and PM concentrations. Finally, Section 7 provides a summary of all results and some perspectives for a possible future continuation of this research effort.

\section{$2 \mathrm{PM}_{2.5}$ and $\mathrm{PM}_{10}$ particles: their origin, composition, size and microphysical properties, and residence times}

Particulate matter (PM) is the term typically used to refer to solid and liquid particles present in the air. Some of these particles are formed naturally, originating from volcanoes, forest and grassland fires, living vegetation, soil dust storms, and sea spray. However, most atmospheric $\mathrm{PM}_{2.5}$ and $\mathrm{PM}_{10}$ sources in polluted environments are linked to human activities. Generally, 
$\mathrm{PM}_{2.5}$ particles are formed from high temperature processes, such as vehicular exhaust, oil and coal combustion processes (internal combustion engines, heating systems, industrial activities, incinerators and thermoelectric power plants, biomass burning), industrial processes, and atmospheric chemical reactions (Harrison et al. 2003; Samara et al. 2003). $\mathrm{PM}_{10}$ particles are usually produced through attrition processes, including mechanical abrasion of crustal material and re-suspension of road and soil dust and brake and tire wear from vehicles (Allen et al. 2001). $\mathrm{PM}_{10}$ contains $\mathrm{PM}_{2.5}$, and - as such - contains not only coarse particles from natural sources and those generated through attrition and abrasion processes but also the smaller particles generated by combustion.

For example, a recent study on air pollution in the Lombardy region, one of the most industrialized areas in Northern Italy where the maximum permitted $\mathrm{PM}_{10}$ concentration threshold is frequently exceeded, revealed that the primary sources of $\mathrm{PM}_{10}$ particles are wood biomass combustion (pellet or wood stoves), responsible for $45 \%$ of the particles present in the air, diesel engines, contributing with $14 \%$, while $13 \%$ results from particles detaching from brake pads and tires (ARPA Lombardia 2017). Another important source of $\mathrm{PM}_{2.5}$ and $\mathrm{PM}_{10}$ particles in this region is represented by the degradation of road surface asphalt. Obviously, the above numbers are considered to be mean values, with the geographical distribution of sources being characterized by a large variability within the region territory. Furthermore, natural sources of particle matter are important in this region, especially those associated with Saharan dust outbreaks, wildfires, and pollen.

Secondary aerosol formation, together with long-range atmospheric transport, represents an additional important source of $\mathrm{PM}_{2.5}$ particles. Secondary components contribute to $\mathrm{PM}_{2.5}$ and $\mathrm{PM}_{10}$ particle formation through chemical reactions, coagulation, and other mechanisms. For example, secondary $\mathrm{PM}_{2.5}$ and $\mathrm{PM}_{10}$ particles can be formed form ammonia $\left(\mathrm{NH}_{3}\right)$ and inorganic acid gases, in combination with NOx and VOC compounds (Marais et al. 2016; Guerra et al. 2014; and Kim et al. 2018).

The definition of $\mathrm{PM}_{2.5}$ and $\mathrm{PM}_{10}$ particles based on their aerodynamic diameter provides an upper size limit for their dimensions, but does not provide any specific information on particles' size distribution. $\mathrm{PM}_{2.5}$ and $\mathrm{PM}_{10}$ measurements are typically carried out with filtration samplers equipped with size-selective inlets capable to discriminate particles smaller than 2.5 and $10 \mu \mathrm{m}$, respectively. Particle number, volume, and mass concentration vary as a function of radius and a comprehensive evaluation of PM potential impact on human health requires an accurate assessment of their size distributions. While information on particle size distribution cannot be inferred from filter-based samples, several literature papers indicate that PM mass distribution in urban background conditions has a predominance of fine particle $\left(\mathrm{PM}_{2.5}\right)$ mass. In industrial areas, the fine mode dominates in combustion-related activities, while the coarse fraction $\left(\mathrm{PM}_{10-2.5}\right)$ is dominant in the case of mechanical activities (Taiwo et al. 2014; Pandolfi et al. 2011), with particle size distributions often found to be bimodal (Seinfeld and Pandis 1998; Verrilli et al. 2010).

Potential effects of suspended PM particles on human health are strongly dependent on their atmospheric life time, or residence time. Atmospheric residence time of PM particles is primarily dependent on their sizes and on atmospheric conditions. Vecchi et al. (2007) reported a typical residence time for atmospheric $\mathrm{PM}_{10}$ particles in urban areas of 10-12 h, while finer aerosols' residence time was estimated to be 18-38 h (Vecchi et al. 2005). However, actual values may be larger especially for finer aerosols for which the residence time depends on the variability of precipitation events (Jaenicke 1982). 


\section{Considerations on inhaled aerosol particles and their potential interaction with the human respiratory system}

\subsection{General remarks}

Suspended aerosols have a significant impact on human health. A mortality analysis carried out by Cui et al. (2003) for the previous coronavirus SARS (SARS-CoV-1) in China pointed out that patients in regions with moderated air pollution levels were more likely to die than those living in regions with low air pollution levels.

Aerosols represent an important vehicle for virus transmission (Sattar and Ijaz 1987; Fabian et al. 2008; Tellier 2009). In order for virus transmission through aerosols to occur, PM particles must carry a sufficient amount of the infectious virus and the virus must survive and remain infectious in the carrier particle for a sufficiently long time before it reaches a susceptible host cell and initiate infection. In general, airborne infectious viruses are difficult to monitor due to their extremely low concentrations in air and because of the inadequacy and lack of accuracy of currently used air samplers.

In general, the primary vehicle of respiratory virus transmission is represented by droplet transmission. This is because, in case of coughing or sneezing, small liquid droplets, which may contain an infective amount of virus, are sprayed from the nose or the mouth. Coughs and sneezes are capable to primarily spread droplets of saliva and mucus (droplet transmission); these particles being typically larger than $5 \mu \mathrm{m}$. Xie et al. (2007) showed that droplets emitted during coughing with sizes of 60-100 $\mu \mathrm{m}$ fall to the ground within $2 \mathrm{~m}$, while smaller size droplets produced during sneezing can travel more than $6 \mathrm{~m}$.

As already anticipated, airborne transmission through virus-laden PM particles is also possible. This relies on tinier particles, produced by talking or even breathing (Duguid 1946; Papineni and Rosenthal 1997). These particles have a longer atmospheric residence time and can travel further. Exhaled breath particles have sizes and concentrations which depend on respiratory patterns (Morawska et al. 2009). Wan et al. (2014) reported sizes smaller than $5 \mu \mathrm{m}, 80 \%$ of which in the range from 0.3 to $1.0 \mu \mathrm{m}$. Fairchild and Stampfer (1987) reported observations of particles exhaled during nose and mouth breathing with sizes in the range $0.1-3 \mu \mathrm{m}$ and a geometric mean concentration of 230 particles per liter during tidal breathing, with $98 \%$ of the measured particles having sizes smaller than $1 \mu \mathrm{m}$. Papineni and Rosenthal (1997) measured particles exhaled during mouth and nose breathing with sizes between 0.3 and $8.0 \mu \mathrm{m}$. They found that more than $84 \%$ of these particles are smaller than $1 \mu \mathrm{m}$. Furthermore, Morawska et al. (2009) demonstrated that vocalization emits up to an order of magnitude more aerosol particles than breathing, with the number of aerosols increasing with increasing speaking volume (Asadi et al. 2020). Small particles (smaller than $5 \mu \mathrm{m}$ ) may also be produced during coughing and sneezing (Fabian et al. 2011). For example, in the case of influenza, $23 \%$ of the particles expelled during coughing were reported to have diameters between 1 and $4 \mu \mathrm{m}$ and $42 \%$ to have diameters smaller than $1 \mu \mathrm{m}$ (Lindsley et al. 2010). Furthermore, suspended microscopic aerosol particles may also consist of residual solid components of evaporated respiratory droplets, which are even tinier and may remain suspended longer (Asadi et al. 2020).

In the evaluation of the potential role of atmospheric aerosols as virus carriers, the capability of atmospheric particles to incorporate small potentially infectious droplets produced during breathing or speaking has to be properly assessed. The primary process allowing atmospheric particles $\left(\mathrm{PM}_{2.5}\right.$ and $\left.\mathrm{PM}_{10}\right)$ to incorporate tiny infectious droplets (smaller than 
$1 \mu \mathrm{m})$ is represented by coagulation. In a coagulation process, two particles collide and eventually adhere, or coalesce, with four fundamental mechanisms potentially determining particles' collisions: i.e., Brownian diffusion, laminar shear, turbulent fluctuations, and particle differential vertical velocity. As a result of coagulation, a larger particle is created from two smaller particles. Consequently, coagulation leads to a reduction in the number of particles and an increase in their sizes (Smoluchowski 1916, 1918). Eventually, small particles exhaled during breathing or speaking, or even coughing or sneezing, each one carrying a limited virus infective amount, may colloid and coalesce with suspended PM particles, eventually leading to PM particles carrying a sufficient virus amount for the infection to be transmitted. Infected PM particles can remain suspended in the air for hours and travel over much longer distances than the large particles emitted during coughing or sneezing, ultimately entering the human respiratory system.

To obtain a better comprehension of the potential role of aerosol particles in virus transmission, the relationship between virus infectivity and particle size has to be carefully studied (Gralton et al. 2011). Few studies are presently available on this topic. For example, Scott and Sydiskis 1976) reported the presence of a lower infectious dose in smaller size particles $(2 \mu \mathrm{m})$ than in larger particles $(10 \mu \mathrm{m})$. Thus, $\mathrm{PM}_{10}$ particles can act as a more efficient carrier than $\mathrm{PM}_{2.5}$ particles. Furthermore, particle size may also affect virus survivability. In this regard, Tyrrell (1967) demonstrated that rhinovirus survives better in coarse particles $(>4 \mu \mathrm{m})$ than in smaller particles $(0-4 \mu \mathrm{m})$, while Appert et al. (2012) found that adenovirus infectivity is better preserved in coarse particles compared with fine particles. Nevertheless, it is to be underlined that coarse particles primarily deposit in the nasal, pharyngeal and laryngeal passages, and in the trachea, while fine particles are primarily deposited in the respiratory bronchioles and alveoli, with important effects in terms of enhanced virus infectivity.

\subsection{Specific remarks for SARS-CoV-2/COVID-19}

Atmospheric aerosols were demonstrated to play an important role in triggering proinflammation and oxidation processes in the lungs of patients infected with SARS-CoV-2. Prolonged exposure to $\mathrm{PM}_{2.5}$ and $\mathrm{PM}_{10}$ has been found to induce acute respiratory inflammation and immunological alterations in these patients (Gemmati et al. 2020; Leung et al. 2020). SARS-CoV-2 is more likely to infect weaker and elderly patients exposed to critical environmental conditions, especially those affected by the simultaneous presence of two or more chronic diseases (Guan et al. 2020). Additionally, patients with compromised immune functions have higher chances to be infected than others. High concentrations of $\mathrm{PM}_{2.5}$ particles may also lead to an over-expression of the viral receptor ACE-2 in the human respiratory system (see papers by Borro et al. 2020; Gemmati et al. 2020; Devaux et al. 2020; Bunyavanich et al. 2020; Leung et al. 2020). It has been speculated that the presence of an elevated number of viral receptors in the host cells may increase the susceptibility to SARS$\mathrm{CoV}-2$ infection. Thus, pollution-induced over-expression of ACE-2 on human airways may favor SARS-CoV-2 infectivity.

The presence of SARS-CoV-2 was successfully detected on $\mathrm{PM}_{10}$ particles in a polluted area in Northern Italy in the period 21 February-13 March 2020 (Setti et al. 2020b, 2020c), i.e., at the time of the pandemic outbreak. In these research works, the presence of SARS-CoV-2 viral RNA was revealed through the detection of the highly specific "RtDR gene" on 8 filters out of 34 samples in outdoor $\mathrm{PM}_{10}$ pollution samples. However, these measurements did not allow to 
assess whether the virus was viable and its amount was sufficiently high to induce infection. Additionally, only fragments of the viral RNA and not the complete viral RNA sequence were detected. It is to be specified that viruses are much smaller than pollution particles, the former typically ranging from 70 to $90 \mathrm{~nm}$ (Kim et al. 2020). At present, there is no definitive, clear, and univocal assessment of the aerosol viral load and the minimum infectious dose necessary to transmit COVID-19, although preliminary ongoing studies on SARS-CoV-2 and previous studies focusing on other viral respiratory pathologies indicated that very low virus loads can initiate infection (Nicas et al. 2005, see Section 4 for more details).

In order to alert the international community on the potential risks of SARS-CoV-2 infection through sneezing and coughing, in March 2020, the World Health Organization issued an official report (WHO 2020a) which advised on the need to maintain a distance of at least $1 \mathrm{~m}$ between individuals. However, this recommendation was not taking into account the potential role of atmospheric particles as virus carriers, i.e., airborne transmission. More recently (July 2020), the World Health Organization has acknowledged the emerging evidence that SARS-CoV-2/COVID-19 can be spread by tiny particles suspended in the air, thus recognizing the potential role of airborne transmission in causing infection within the recipient individuals as a result of the inhalation of aerosol particles containing a sufficient virus quantity (WHO 2020b). Airborne transmission has been hypothesized to more likely characterize symptomless infected patients (Rothe et al. 2020; He and Han 2020). Evidence of the importance of airborne transmission in symptomless infected patients was reported for previous respiratory viruses (Fernstrom and Goldblatt 2013). At present, no study is available specifically focusing on the analysis of breath and cough samplings from patients infected with SARS-CoV-2/COVID-19, but SARS-CoV-2 has been detected in the indoor air samples in hospitals (Liu et al. 2020; Santarpia et al. 2020).

The incorporation of viruses by atmospheric particles through coagulation is a process with a high efficiency variability. SARS-CoV-2 stability in aerosols was recently estimated by van Doremalen et al. (2020), who determined virus decay rates using a Bayesian regression model. Results from these authors indicate that SARS-CoV-2 remains viable in aerosols for a duration of $\sim 3 \mathrm{~h}$, with an half-life of $1.1 \mathrm{~h}$.

The effectiveness of airborne transmission strongly depends on SARS-CoV-2 infectious dose, which represents the virus amount needed to initiate an infection. The infectious dose is highly variable for different respiratory viruses, ranging from just 10 virus-laden particles - for example, for adenovirus - to thousands for other human viruses (Lakdawala and Gaglia 2020). However, the exact number of SARS-CoV-2 viruses needed to trigger COVID-19 infection has not been determined yet and its determination represents an important topic for scientific investigation. The intense worldwide pandemic outbreak of COVID-19 clearly testifies that SARS-CoV-2 is very contagious, but this may indicate either that a limited number of viruses are needed for infection (low infectious dose) or that infected people release a lot of viruses in the external environment.

\section{Assessment of the potential role of airborne transmission}

In the above sections, we provided a detail overview of the research knowledge and scientific literature on atmospheric particulate pollution and its potential interaction with the human respiratory system. In what follows, the paper methodology is illustrated and developed, which includes a model component, an observational component, and a statistical analysis component. 
An analytical model has been developed in order to get a rough quantitative assessment of the potential role of airborne transmission through virus-laden PM particles in conveying SARS-CoV-2 in the human respiratory system and trigger COVID-19. The purpose of the model is to assess this additional transmission vehicle with a specific attention to indoor conditions. A proper simulation of this process requires specific information on exhaled particles' sizes and concentrations, their residence time, transported viral dose, and minimum infective dose. The model simulates particle collection efficiency, accounting for the combined effect of collision and coagulation efficiencies in the formation of virus-transmitting PM particles. The model provides a quantitative assessment of the role of Brownian diffusion, laminar shear, turbulent fluctuations, and gravitational and drag forces.

Concerning the transported viral dose and the minimum infective dose, only limited virological information is available in the open international literature specifically for SARS$\mathrm{CoV}-2$. However, for the purpose of getting a rough estimate of the importance of airborne transmission through virus-laden $\mathrm{PM}_{2.5}$ and $\mathrm{PM}_{10}$ particles, missing specific information on the above quantities for SARS-CoV-2 can be replaced with analogous information from other viral pathologies. This obviously leads to results affected by a large degree of uncertainty.

The developed analytical model relies on the following assumptions/hypotheses.

- Outdoor $\mathrm{PM}_{2.5}$ and $\mathrm{PM}_{10}$ concentrations are assumed to be 60 and $70 \mu \mathrm{g} / \mathrm{m}^{3}$, respectively; these values are representative of the high particulate pollution conditions observed in Northern Italy in the weeks preceding the pandemic outbreak (values exceeding $60 \mu \mathrm{g} / \mathrm{m}^{3}$ for $\mathrm{PM}_{10}$ and $\mathrm{PM}_{2.5}$ were observed 8 and 6 times, respectively, during the month of February 2020 in all metropolitan cities in Lombardia, see following Section 6.1). Outdoor $\mathrm{PM}_{2.5}$ and $\mathrm{PM}_{10}$ concentrations are assumed to be also present indoor. In this regard, it is to be specified that $\mathrm{PM}_{2.5}$ and $\mathrm{PM}_{10}$ pollution concentrations in outdoor environments are frequently found to be highly correlated with indoor concentrations (Mohammed et al. 2015; Pallarés et al. 2019; Saramak 2019), and are often characterized by comparable concentrations (Massey et al. 2009). Thus, the presence of high outdoor $\mathrm{PM}_{2.5}$ and $\mathrm{PM}_{10}$ pollution levels is likely to translate into high indoor $\mathrm{PM}_{2.5}$ and $\mathrm{PM}_{10}$ concentrations, which is what we assume.

- SARS-CoV-2 is assumed to remain viable in aerosols for $\sim 3 \mathrm{~h}$ in indoor conditions, with a half-life of $1.1 \mathrm{~h}$ and a reduction in infectious titer from $10^{3.5}$ to $10^{2.7} \mathrm{TCID} 50$ per liter of air (van Doremalen et al. 2020).

- The considered indoor space has a volume of $50 \mathrm{~m}^{3}$ and includes 5 individuals, all of them but one asymptomatic infected patients.

- $80 \%$ of the particles exhaled during breathing or speaking are assumed to have diameters smaller than $1 \mu \mathrm{m}$ (see above in Section 3.1 in more detail: Wan et al. 2014; Fairchild and Stampfer 1987; Papineni and Rosenthal 1997), while $40 \%$ of the particles expelled during coughing are assumed to have diameters smaller than $1 \mu \mathrm{m}$ (Lindsley et al. 2010).

- The number of particles exhaled on tidal breathing by subjects infected by a respiratory virus is assumed to be 5000 per liter ( 7200 particles per liter were reported by Fabian et al. (2011) for human rhinovirus (HRV), while 4644 particles per liter were reported by Wan et al. (2014) for mechanically ventilated patients affected by pneumonia); the number of particles produced on coughing by influenza-infected patients was estimated to be 75,400 particles per cough (Lindsley et al. 2012), which is the number assumed in the model. 
- Tidal volume of human breath and respiratory rate are assumed to be $500 \mathrm{ml}$ and 15 breaths/min, respectively (Carroll 2007; Riediker and Tsai 2020); thus, 3-h pulmonary ventilation corresponds to a volume of $1350 \mathrm{l}$; coughing volume and rate are assumed to $250 \mathrm{ml}$ and 2 coughs/min, respectively (Hsu et al. 1994); thus, air expelled during 3-h coughing corresponds to a volume of 901 .

- The velocity of particles produced on breathing and coughing is assumed to be 1 and $10 \mathrm{~m} \mathrm{~s}^{-1}$, respectively (breathing particle velocities in the range $1-7 \mathrm{~m} \mathrm{~s}^{-1}$ were estimated by Tsuda et al. (2013), while coughing particle velocities in the range $10-30 \mathrm{~m} \mathrm{~s}^{-1}$ and in the range $20-90 \mathrm{~m} \mathrm{~s}^{-1}$ were estimated by Bourouiba (2020) and La Rosa et al. (2013), respectively).

The following equations and additional hypotheses are considered in our simplified model. Small particles exhaled during breathing or speaking and coughing may colloid and coalesce on suspended $\mathrm{PM}_{2.5}$ and $\mathrm{PM}_{10}$ particles. We assume liquid water to be the predominant component of exhaled particles, while $\mathrm{PM}_{2.5}$ and $\mathrm{PM}_{10}$ particles are assumed to be primarily carbonaceous/soot particles (density $=1.8-2.1 \times 10^{3} \mathrm{~kg} \mathrm{~m}^{-3}$ ), with a high affinity to water, i.e., a high hygroscopicity (Liu et al. 2013; Henning et al. 2012). Particles are subject to three major classes of motion: uniform motion (primary associated with the gravitational and drag forces), diffusive motion (Brownian diffusion), and the motion of the air mass in which the particle is embedded (wind, turbulence, convective air currents, etc.). The dynamical regime of the suspended particles can be defined through the Knudsen number:

$$
K_{n}=\frac{2 \lambda}{d}
$$

where $\lambda$ is the mean free path of the suspending gas and $d$ is the diameter of the particle (Baron and Willeke 2001). The free molecular regime characterizes particles which are small compared to the mean free path of the suspending gas, i.e., Kn >> 1 (De Carlo 2004). Particles in this regime tend to follow ballistic streamlines. The continuum regime characterizes particles which are large compared to the mean free path of the suspending gas $(\mathrm{Kn}<<1$, De Carlo 2004), with the gas acting as a continuous fluid flowing round the particle. The mean free path of air molecules is about $0.07 \mu \mathrm{m}$ (Jennings 1988); thus, the motion of the suspended particles considered in the present study is governed by the continuum regime equations.

In the present continuum regime, the number of colliding aerosol particles is given by the expression (Morris 2002; Friedlander 1977):

$$
N_{a b}=\alpha \times \beta(a, b) \times n_{a} \times n_{b}
$$

with $n_{a}$ and $n_{b}$ being the concentrations of the two classes of colliding particles $a$ and $b, \alpha$ being the collision or attachment efficiency, and $\beta(a, b)$ being the collision frequency in the continuum regime. The collision efficiency is defined as (Phan-Cong and Dinh-Van 1973):

$$
\alpha=\left(\frac{x}{r_{a}+r_{b}}\right)^{2}
$$

with $x$ being the largest initial horizontal separation of the falling droplet centers and $r_{a / b}$ being the radii of the two colliding particles. The collision efficiency is taken equal to 1 .

The collision frequency includes four distinct terms associated with four distinct processes: the Brownian motion, the fluid laminar and turbulent shears, and the differential settling. The 
Brownian motion term $\beta_{B}(a, b)$ of the collision frequency can be determined through the expression (Morris 2002):

$$
\beta_{B}(a, b)=4 \pi\left(r_{a}+r_{b}\right)\left(D_{a}+D_{b}\right)
$$

with $D_{a}+D_{b}$ being the effective diffusion coefficient between particles. Diffusion coefficients can be determined through the Stokes-Einstein relation (Seinfeld and Pandis 1998):

$$
D_{a / b}=\frac{k T C c}{6 \pi \mu r_{a / b}}
$$

with $k$ being the Boltzmann constant $\left(1.38 \mathrm{~J} \mathrm{~K}^{-1}\right), C_{c}$ being the slip correction factor (Seinfeld and Pandis 1998), and $\mu$ being the viscosity of air $\left(1.8 \times 10^{-5} \mathrm{~kg} \mathrm{~m}^{-1} \mathrm{~s}^{-1}\right)$. In air at $293 \mathrm{~K}$ and $1 \mathrm{~atm}, D=1.29 \times 10^{-11}$ for $0.1-\mu \mathrm{m}$ radius particles, $D=5.05 \times 10^{-12}$ for $1-\mu \mathrm{m}$ radius particles, $D=4.92 \times 10^{-12}$ for 2.5 - $\mu \mathrm{m}$ radius particles, and $D=1.20 \times 10^{-12}$ for $10-\mu \mathrm{m}$ radius particles.

The laminar fluid shear term $\beta_{L S}(a, b)$ of the collision frequency can be expressed as (Stumm 1992):

$$
\beta_{L S}(a, b)=1.33 G\left(r_{a}+r_{b}\right)^{3}
$$

with $G$ being the mean velocity gradient. Values of $G$ in the particle size interval of interest for our computations $(0.1 \mu \mathrm{m} \leq \mathrm{r} \leq 5 \mu \mathrm{m})$ vary in the range 0.46-10 $\mathrm{s}^{-1}$ (Pruppacher and Klett 1997). The turbulent fluid shear term $\beta_{T S}(a, b)$ of the collision frequency can be expressed as (Pruppacher and Klett 1997):

$$
\beta_{T S}(a, b)=1.3 \mu\left(r_{a}+r_{b}\right)^{3}
$$

with $\mu$ being the turbulent shear rate. Typical values of $\mu$ are in the range 4-28 s ${ }^{-1}$ (Ackerman 1967). Finally, the differential sedimentation term $\beta_{S}(a, b)$ of the collision frequency can be expressed as (Findheisen 1939):

$$
\beta_{S}(a, b)=\pi\left(r_{a}+r_{b}\right)^{2}\left|v_{a}-v_{b}\right|
$$

with $v_{a}$ and $v_{b}$ being the terminal settling velocities of the two classes of colliding particles $a$ and $b$. As a result of gravitational settling, in combination with drag, particles reach a constant velocity $v_{t}$, called "terminal settling velocity." The time $\tau$ required for a particle to reach its terminal settling velocity varies as a function of the particle size, being around $8 \times 10^{-5} \mathrm{~s}$ for $\mathrm{PM}_{2.5}$ particles and around $1.2 \times 10^{-3} \mathrm{~s}$ for $\mathrm{PM}_{10}$ particles (Seinfeld and Pandis 1998). The terminal settling velocity can be determined through the expression:

$$
v_{a / b}=\frac{r^{2}\left(\rho-\rho_{w}\right) g C_{c}}{9 \mu}
$$

with $r$ being the particle radius; $\rho$ being the PM particle density $\left(1.27-1.78 \times 10^{3} \mathrm{~kg} \mathrm{~m}^{-3}\right.$ for black carbon, $1.8-2.1 \times 10^{3} \mathrm{~kg} \mathrm{~m}^{-3}$ for soot); $\rho_{w}$ being the density of the particles exhaled when breathing, speaking, coughing, and sneezing (assumed to be composed of liquid water, $\left.0.997 \times 10^{3} \mathrm{~kg} \mathrm{~m}^{-3}\right) ; g$ being the gravity acceleration $\left(9.8 \mathrm{~m} \mathrm{~s}^{-1}\right) ; C_{c}$ being the slip correction factor (with values varying around 1 in the considered particle size range, Seinfeld and Pandis 1998); and $\mu$ being the viscosity of air $\left(1.8 \times 10^{-5} \mathrm{~kg} \mathrm{~m}^{-1} \mathrm{~s}^{-1}\right) . \mathrm{PM}_{2.5}$ and $\mathrm{PM}_{10}$ particles have larger terminal settling velocities than particles exhaled while breathing, speaking, and part of those emitted when coughing. As a result of this differential velocity, $\mathrm{PM}_{2.5}$ and $\mathrm{PM}_{10}$ particles 
eventually collide with exhaled particles. The above expression is applicable to motions characterized by Reynolds numbers $\operatorname{Re}<0.1$ or particles smaller than about $20 \mu \mathrm{m}$ (Seinfeld and Pandis 1998).

Expression (6) has also been extended to the coalescence process associated with the primarily horizontal component of the initial part of the motion of the exhaled breathing and coughing particles; this motion is treated as a uniform motion as the one associated with gravitational settling. "Horizontal" coalescence was found to play an important role also in other processes commonly considered to be dominated by "vertical" coalescence, as those associated with convective cloud formation (Khain and Pinsky 1995).

Based on the above analytical expressions, which describe the different microphysical processes involving $\mathrm{PM}_{2.5}$ and $\mathrm{PM}_{10}$ particles and the small particles emitted during breathing, speaking, or coughing, it is possible to determine the number of events associated with each coalescence process. This number is highly variable in dependence of the considered process and the size of the breathing and coughing particles colliding with $\mathrm{PM}_{2.5}$ and $\mathrm{PM}_{10}$ particles. The overall number of coalescence processes of breathing and coughing particles on $\mathrm{PM}_{2.5}$ and $\mathrm{PM}_{10}$ particles is illustrated in Fig. 1. The overall number of coalescence processes is highly dependent on the size of the breathing and coughing particles. As the contribution of the different processes may strongly vary as a function of the sizes of breathing and coughing

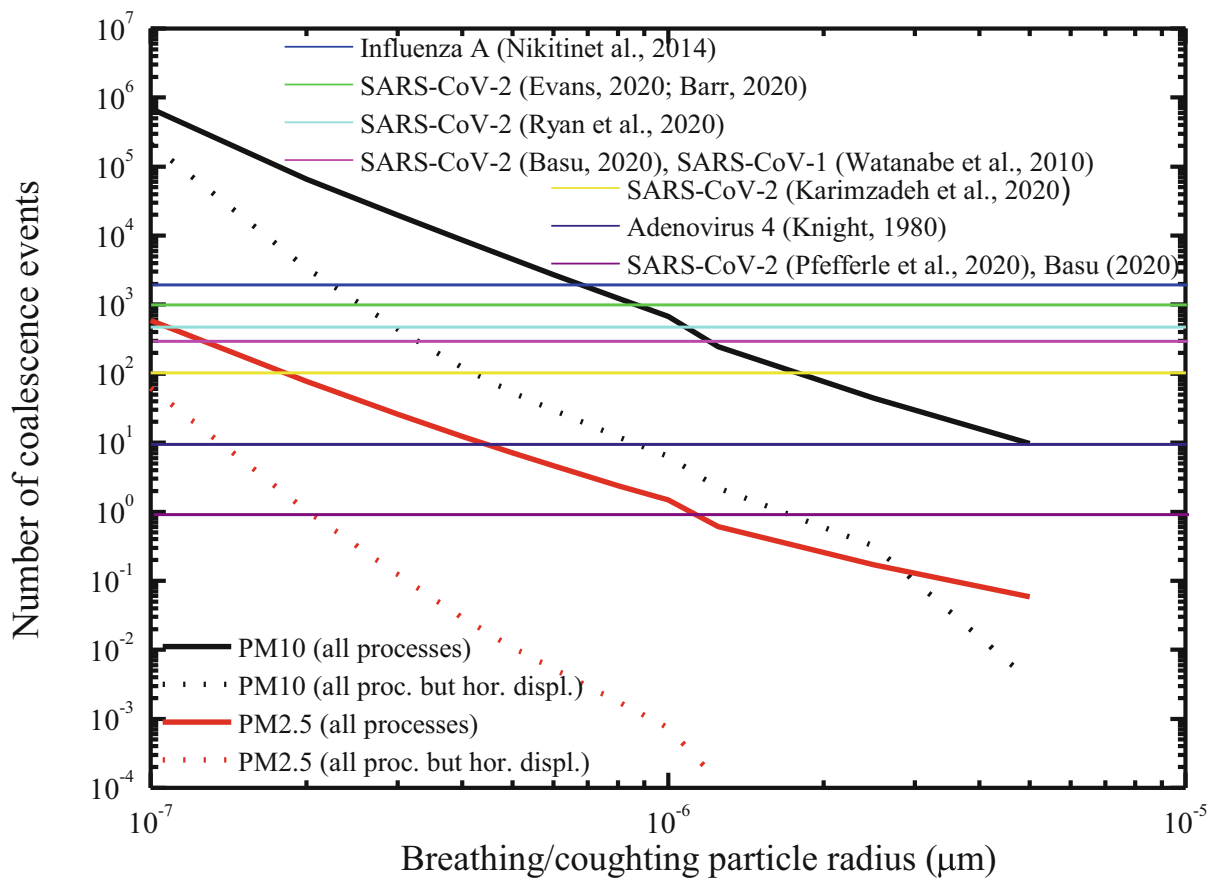

Fig. 1 Overall number of coalescing events of breathing and coughing particles onto $\mathrm{PM}_{2.5}$ (red lines) and $\mathrm{PM}_{10}$ (black lines) particles as a function of the size of the breathing and coughing particles. Two lines are present for each particle size: one (solid line) representing the overall number of coalescing events associated with all considered coagulation processes, the other one (dotted line) representing the number of coalescing events when excluding the coagulation process associated with the primarily horizontal component of the initial motion of exhaled particles. The horizontal lines in the figure represent the minimum infectious doses of SARS-CoV-2 and other respiratory viruses 
particles, both axes in the figure are represented in log-scale. Figure 1 includes two lines for each particle type: one line represents the overall number of coalescence events associated with all the abovementioned coalescence processes, including the one associated with the horizontal component of the initial motion of exhaled breathing and coughing particles; the other line represents the number of coalescing events associated only with Brownian motion, fluid laminar and turbulent shear, and differential settling. Both lines have been reported as in fact the contribution associated with the initial horizontal motion of exhaled breathing and coughing particles appears to be predominant with respect to the other processes, and consequently, results from the model need to be carefully discussed accounting for these differences.

Results in Fig. 1 clearly reveal that the number of coalescence events strongly decreases with the increasing size of breathing/coughing particles. Specifically, for $\mathrm{PM}_{10}$ particles, the number decreases from $7 \times 10^{5}$ to $6.5 \times 10^{4}, 4.5 \times 10^{3}, 7 \times 10^{2}, 80$ and 10 for breathing/ coughing particle sizes increasing from 0.1 to $0.2,0.5,1,2$, and $5 \mu \mathrm{m}$, respectively. When uniform horizontal coalescence is disregarded, the number of breathing and coughing particles colliding on $\mathrm{PM}_{10}$ particles decreases from $2.5 \times 10^{5}$ to $3.5 \times 10^{3}, 45,6,0.6$, and $4 \times 10^{-3}$ for breathing/coughing particle sizes increasing from 0.1 to $0.2,0.5,1,2$, and $5 \mu \mathrm{m}$, respectively. For $\mathrm{PM}_{2.5}$ particles, the number of coalescing events is approximately 3 orders of magnitude smaller than for $\mathrm{PM}_{10}$ particles. Specifically, the number of coalescence events decreases from $7 \times 10^{2}$ to $80,7,1.5,0.25$, and $6 \times 10^{-2}$ for breathing/coughing particle sizes increasing from 0.1 to $0.2,0.5,1,2$, and $5 \mu \mathrm{m}$, respectively, while when removing uniform horizontal coalescence, the number of coalescence events decreases from 65 to $1.2,1.2 \times 10^{-2}$, and $7 \times$ $10^{-4}$ for breathing/coughing particle sizes increasing from 0.1 to $0.2,0.5$, and $1 \mu \mathrm{m}$.

The minimum infectious dose of viable SARS-CoV-2 required to cause infection is not exactly known yet, but there are a number of estimates, together with information extracted from studies on other respiratory viruses. Specifically, the minimum infectious dose was estimated by Evans (2020) and Barr (2020) to be $~ 1000$, while Ryan et al. (2020) estimated a minimum number of 500 infectious particles to be sufficient to activate infection. A value of 300 is suggested by Basu (2020), while a value of 100 was conjectured by Karimzadeh et al. (2020). Pfefferle et al. (2020) and Basu (2020) hypothesized that even a single viral particle can be sufficient to initiate SARS-CoV-2 infection. Other respiratory viruses were found to be characterized by higher or lower infectivity levels. Specifically, Nikitin et al. (2014) suggested a value of 1950 for influenza A, Watanabe et al. (2010) estimated a minimum infectious dose value of 280 virus particles for SARS-CoV-1, while adenovirus type 4 was found to approach an infectivity of 10 virus particles or less (Knight 1980). All these different values are reported in Fig. 1 as horizontal lines. The figure clearly reveals that the number of coalescing events of breathing/coughing particles onto $\mathrm{PM}_{2.5}$ and $\mathrm{PM}_{10}$ particles is exceeding most of the infectious dose values indicated above over a large size range for the colliding breathing/coughing particles. This is particularly true for $\mathrm{PM}_{10}$ particles, where the number of coalescing events is approximately 3 orders of magnitude higher than for $\mathrm{PM}_{2.5}$ particles. Specifically, the number of breathing and coughing particles coalescing on $\mathrm{PM}_{10}$ particles exceeds the highest SARS-CoV-2 infectious dose value (1000) for breathing/coughing particle sizes up to $0.9 \mu \mathrm{m}$, while the number of breathing/coughing particles coalescing on PM10 particles exceeds the SARS-CoV-2 infectious dose value of 10 for breathing/coughing particles over the size interval $0.1 \mu \mathrm{m} \leq \mathrm{r} \leq 5 \mu \mathrm{m}$. In case the uniform horizontal coalescence mechanism is ignored, the number of breathing and coughing particles coalescing on $\mathrm{PM}_{10}$ particles exceeds the highest SARS-CoV-2 infectious dose value for breathing/coughing particle sizes up to 
$0.15 \mu \mathrm{m}$, while the number of coalescing events exceeds the lowest SARS-CoV-2 infectious dose value (1) for breathing/coughing particle sizes up to $2 \mu \mathrm{m}$. Finally, the number of breathing and coughing particles coalescing on $\mathrm{PM}_{2.5}$ particles exceeds the minimum infectious doses of 100, and 10 and 1 for breathing/coughing particle sizes up to $0.18,0.45$, and $1.2 \mu \mathrm{m}$, respectively.

The above results assume that all breathing and coughing particle coalescing on $\mathrm{PM}_{2.5}$ and $\mathrm{PM}_{10}$ particles carry at least one virion, i.e., a complete viral particle. This is obviously a very uncertain assumption as in fact this information is not specifically available for SARS-CoV-2. The number of virions carried by suspended particles is strongly dependent on their size, the value increasing with increasing size. An indirect estimate of this quantity can be obtained from the data available on the number of virus copies present in SARS-CoV-2 sputum samples, with a value of $2.35 \times 10^{9}$ copies per milliliter reported by Wölfel et al. (2020) and a value up to $1.34 \times 10^{11}$ copies per milliliter reported by Pan et al. (2020). Considering the same virus concentration in the sputum and in the exhaled particles, the number of virions carried by each suspended particle is in the range $0.0012-0.0702$ for a particle radius of $0.5 \mu \mathrm{m}$, in the range $0.0098-0.56$ for a particle radius of $1 \mu \mathrm{m}$, in the range $0.079-4.49$ for a particle radius of $2 \mu \mathrm{m}$, and in the range 1.23-70.16 for a particle radius of $5 \mu \mathrm{m}$. These numbers confirm that airborne transmission through virus-laden PM particles represents a potentially important vehicle for virus transmission in particulate pollution conditions which may effectively contribute to the infectious spread.

All in all, the results from the present analytical model, in combination with measurements of $\mathrm{PM}_{2.5}$ and $\mathrm{PM}_{10}$ particulate pollution, and virological and epidemiologic information from literature papers, allow establishing the important potential role of airborne transmission in conveying a contagious virus amount in the respiratory system. This transmission mechanism is primarily associated with the small particles emitted during breathing, speaking, and partially also during coughing and sneezing, each carrying a limited virus infective amount, which may colloid and coalesce with suspended PM particles, eventually leading to PM particles carrying a sufficient virus amount for the infection to be transmitted.

While evidence of the presence and viability of SARS-CoV-2 and other virus particles has been reported in the literature for laboratory-controlled indoor conditions (van Doremalen et al. 2020), no information is available on the effect of variable temperature, humidity, UV radiation, atmospheric stability, transport conditions, and atmospheric oxidant capacities in atmospheric outdoor environments (Lolli et al. 2020). This implies that airborne transmission through virus-transmitting PM particles, while having a more uncertain role in outdoor conditions, is likely to be important in indoor environments.

Finally, while airborne transmission through virus-laden PM particles represents a potentially important vehicle for virus transmission in particulate pollution conditions, it is necessary to emphasize that, even in unpolluted conditions, in unventilated indoor spaces with a number of infected individuals, especially asymptomatic ones, the simple ingestion of briefing and coughing particles exhaled by these individuals may represent an important vehicle for virus transmission.

\section{Air quality datasets}

$\mathrm{PM}_{10}$ measurements considered in this paper for comparison with epidemiologic parameters are from the Italian ground-based network of air quality monitoring stations which is run by different regional and provincial environment agencies. Filter-based samplers of $\mathrm{PM}_{2.5}$ and 
$\mathrm{PM}_{10}$ particles, equipped with size-selective inlets capable to discriminate particles smaller than 2.5 and $10 \mu \mathrm{m}$, respectively, represent the primary approach to monitor atmospheric particulate matter in the ground network of air quality monitoring stations. Data within this network are collected in a coordinated manner based on a well-established common procedure. Consequently, differences between measurements from different sensors to be attributed to sensors' biases are assumed to be negligible.

The effective impact of $\mathrm{PM}_{2.5}$ and $\mathrm{PM}_{10}$ particles on COVID-19 infection outbreak strongly depends on particle persistency in the air, i.e., on the duration of the exposure of the human respiratory system to particulate pollution throughout the day. However, in most cases, gravimetric measurements are based on the analysis of filters collecting particulate material over the duration of the day, and, consequently, lack in temporal resolution. Thus, ground PM measurements are scarcely usable when particle concentration variability during a specific day or at specific times of the day needs to be inferred. Alternative measurement techniques or datasets have then to be considered to eventually assess the actual duration of the human respiratory system pollution exposure throughout the day. Particularly effective in this direction is the use of $\mathrm{PM}_{2.5}$ and $\mathrm{PM}_{10}$ data from near-real-time ECMWF-CAMS analysis, which are provided with hourly resolution and a grid size of $10 \times 10 \mathrm{~km}$. CAMS near-real-time reanalysis, used in this research effort, is the most recent global reanalysis of atmospheric composition and air quality data, which is produced by the Copernicus Atmosphere Monitoring Service (CAMS) of the European Centre for Medium-Range Weather Forecasts (ECMWF). $\mathrm{PM}_{2.5}$ and $\mathrm{PM}_{10}$ data from ECMWF-CAMS near-real-time reanalysis is based on the reanalyses from a number of state-ofthe-art numerical air quality models developed in Europe. These models, each one relying on its own data assimilation system, perform daily retrospective analyses of pollutants near the surface by assimilating 1-day-old observations. Surface observations, collected on a daily basis from the European Environmental Agency (EEA), are the main source of assimilated data. The analyses from all partner models are combined via an ensemble approach, consisting in calculating the median value of the individual outputs. ECMWF-CAMS near-real-time reanalysis data, while characterized by a high time $(1 \mathrm{~h})$ and horizontal $(10 \times 10 \mathrm{~km})$ resolutions, may result less accurate than the co-located simultaneous ground-based in situ measurements at the exact location of the ground station as a consequence of its lower horizontal resolution.

In the next section, geo-located total column and tropospheric $\mathrm{NO}_{2}$ and $\mathrm{HCHO}$ column measurements are also reported. These measurements are collected by the satellite sensor TROPOMI onboard Copernicus Sentinel-5P. TROPOMI is a non-scanning nadir-viewing, passive grating imaging spectrometer, with swath width of $2600 \mathrm{~km}$ and a spatial sampling of $7 \times 7$ $\mathrm{km}$, covering wavelength bands between the ultraviolet and the shortwave infrared. The satellite is located on a near-polar, sun-synchronous orbit, with high inclination (approximately $98.7^{\circ}$ ) at an altitude of approximately $824 \mathrm{~km}$, with nadir overpasses at 13:30 local time (ascending node crossing time). The satellite performs 14 orbits per day, 227 orbits per cycle, and its orbital cycle, i.e., the time taken for the satellite to pass over the same geographical point on the ground, is 16 days. In addition to $\mathrm{NO}_{2}$ and $\mathrm{HCHO}$, TROPOMI also measures $\mathrm{O}_{3}, \mathrm{SO}_{2}, \mathrm{CO}$, and $\mathrm{CH}_{4}$; all datasets are provided with a grid size of $3.5 \times 3.5 \mathrm{~km}$. Observations of $\mathrm{NO}_{2}$ and $\mathrm{HCHO}$ from TROPOMI are illustrated in this paper with the only purpose of confirming their presence during the large particulate pollution outbreak events observed in mid-February 2020 and arguing on their potential role in secondary aerosol formation. In this regard, it is specified that, while the conversion of $\mathrm{NO}_{2}$ into particulate phase nitrate is a well-understood physicochemical process, characterized by reasonably well-known conversion rates, volatile organic compounds, as formaldehyde (HCHO), undergo atmospheric degradation processes generating oxidized products, 
which ultimately may or may not contribute to secondary organic aerosol formation. Formaldehyde may contribute to $\mathrm{O}_{3}$ pollution through photochemical reactions (Carter 1994; Russell et al. 1995), which favor the formation of secondary organic aerosol via the provision of $\mathrm{OH}$ radicals (Yang et al. 2018). Atmospheric formaldehyde is a product of isoprene oxidation (Palmer et al. 2003) and isoprene emitted by vegetation is an important precursor of secondary organic aerosols (Marais et al. 2016). Direct HCHO emission, closely related to CO emission, takes also place as a result of incomplete combustion processes.

\section{Results}

\subsection{Evolution of $\mathrm{PM}_{2.5}$ and $\mathrm{PM}_{10}$ concentrations throughout the month of February 2020}

Figure 2 shows $\mathrm{PM}_{2.5}$ and $\mathrm{PM}_{10}$ concentrations at 00:00 UTC on 17 February 2020, as provided by the near-real-time ECMWF-CAMS analysis. The figure covers an area encompassing the Italian peninsula and portions of the surrounding nations. This figure represents the pollution situation in the central day of the second of the three major particulate matter pollution outbreaks (15-19 February 2020) which preceded the pandemic onset. The figure clearly reveals the presence of enhanced $\mathrm{PM}_{2.5}$ and $\mathrm{PM}_{10}$ concentrations over large portions of the Po Valley, with levels exceeding $60 \mu \mathrm{g} / \mathrm{m}^{3}$ for both species. These values are largely exceeding the limits of $25 \mu \mathrm{g} / \mathrm{m}^{3}$ for $\mathrm{PM}_{2.5}$ and $50 \mu \mathrm{g} / \mathrm{m}^{3}$ for $\mathrm{PM}_{10}$ defined by the WHO Air quality guideline (WHO 2005). This figure provides a snapshot of the highly polluted conditions present in the Po Valley shortly before (1-2 weeks) the pandemic outbreak. Figure 3 shows $\mathrm{PM}_{2.5}$ and $\mathrm{PM}_{10}$ concentrations at 00:00 UTC on 29 February 2020, again from the near-real-time ECMWF-CAMS analysis. This figure provides a snapshot of the pollution situation few days after the shutdown of all vehicular and industrial activities associated with the lockdown in Northern Italy on 25 February 2020. The selected date (29 February 2020) is intended to be indicative of the low PM concentration conditions found on a number of consecutive days in the final part of February 2020. $\mathrm{PM}_{2.5}$ and $\mathrm{PM}_{10}$ concentrations are found to have dropped abruptly, with levels not exceeding $15-20 \mu \mathrm{g} / \mathrm{m}^{3}$ for both species.

Figure 4 illustrates the $\mathrm{NO}_{2}$ concentrations from TROPOMI onboard the Copernicus Sentinel-5P at 12:30 UTC on 17 February 2020 for the same area considered in Figs. 2 and 3 . The figure reveals the presence of peak $\mathrm{NO}_{2}$ values over the metropolitan area of Milan $(5 \times$ $\left.10^{-4} \mathrm{~mol} \mathrm{~m}^{-2}\right)$, but high values, in excess of $1.5-2 \times 10^{-4} \mathrm{~mol} \mathrm{~m}^{-2}$, are also observed over large portions of the Po Valley. Peak values of lower amplitude $\left(\sim 1.5 \times 10^{-4} \mathrm{~mol} \mathrm{~m}^{-2}\right)$ are also found over the metropolitan areas of Rome and Napoli. These measurements testify the important potential contribution of secondary aerosol formation in the observed $\mathrm{PM}_{2.5}$ and $\mathrm{PM}_{10}$ pollution event. Figure 5 illustrates the $\mathrm{HCH}$ (formaldehyde) concentrations from TROPOMI at the same time and over the same geographical area considered in Figs. 2, 3, and 4. Values around $2.5 \times 10^{-4} \mathrm{~mol} \mathrm{~m}^{-2}$ are found in the upper portion of the Po Valley, in coincidence with the high $\mathrm{PM}_{2.5}$ and $\mathrm{PM}_{10}$ concentrations, thus further supporting the hypothesis of the potential role played by secondary aerosol formation. Due to the low signal-to-noise ratios of $\mathrm{NO}_{2}$ and $\mathrm{HCHO}$ concentration measurements, data in Figs. 4 and 5 are 7-day averages centered on the reference day, i.e., on 17 February 2020, thus including the data from 14 to 20 February 2020. 

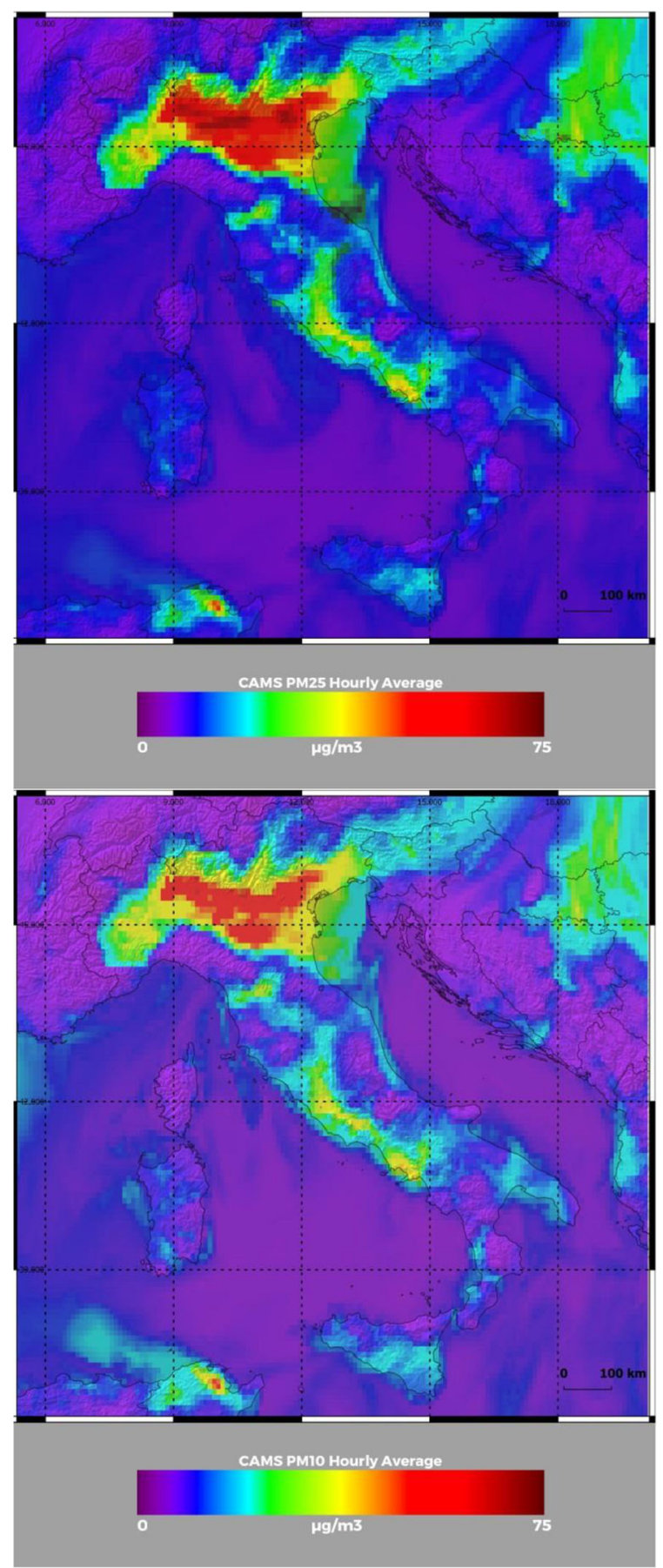

Fig. $2 \mathrm{PM}_{2.5}$ (upper panel) and $\mathrm{PM}_{10}$ (lower panel) concentrations at 00:00 UTC on 17 February 2020 from nearreal-time ECMWF-CAMS analysis over an area encompassing the Italian peninsula and portions of the surrounding nations 
Measurements collected over the period January-February 2020 by the ground-based network of air quality monitoring stations (not shown here) reveal that threshold levels for $\mathrm{PM}_{10}\left(<50 \mu \mathrm{g} / \mathrm{m}^{3}\right)$ were exceeded on 20-35 days in large portions of the Po Valley, with levels in excess of $80 \mu \mathrm{g} / \mathrm{m}^{3}$ occasionally observed in the 1-3 weeks preceding the contagious activation around 25 February 2020. Threshold values for $\mathrm{PM}_{2.5}$ indicted in WHO air quality guidelines $\left(<25 \mu \mathrm{g} / \mathrm{m}^{3}\right)$ were exceeded on more than 40 days over the period JanuaryFebruary 2020 in large portions of the Po Valley (again not shown here), with levels up to $70 \mu \mathrm{g} / \mathrm{m}^{3}$ observed in the weeks preceding the contagious activation.

The variability of $\mathrm{PM}_{2.5}$ and $\mathrm{PM}_{10}$ concentrations over the month of February 2020 for several metropolitan cities in Lombardia (Bergamo, Brescia, Cremona, Milano, Monza, and Pavia, see locations in the map in Fig. 6) has been considered. Specifically, Fig. 7 illustrates $\mathrm{PM}_{2.5}$ and $\mathrm{PM}_{10}$ concentration measurements during the month of February 2020 from three ground-based stations, one in Bergamo (via Meucci, $45^{\circ} 41^{\prime} 24^{\prime \prime} \mathrm{N}, 09^{\circ} 38^{\prime} 28^{\prime \prime} \mathrm{E}$ ) and two in

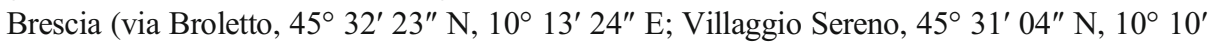
$41^{\prime \prime} \mathrm{E}$ ), included in the network of air quality monitoring stations run by the regional and provincial environment agencies. In the figure, these measurements are compared with the corresponding data from the hourly near-real-time ECMWF-CAMS analysis. ECMWFCAMS analysis well reproduces $\mathrm{PM}_{2.5}$ and $\mathrm{PM}_{10}$ concentration values measured by the ground-based stations, thus revealing its capability to capture the high-resolution variability of $\mathrm{PM}_{2.5}$ and $\mathrm{PM}_{10}$ concentrations within each single day in this period. This comparison clearly highlights that very high peak concentration values (up to $\sim 80 \mu \mathrm{g} / \mathrm{m}^{3}$ ) are occasionally observed at specific times of the day, such peaks not being detected in the daily-averaged ground station measurements.

Figure 8 illustrates the variability of $\mathrm{PM}_{2.5}$ and $\mathrm{PM}_{10}$ concentrations over the month of February 2020 for several metropolitan cities in Lombardia (Bergamo, Brescia, Cremona, Milano, Monza, and Pavia) as obtained from near-real-time ECMWF-CAMS analysis. Several air quality monitoring stations are considered, when available, for each city. The figure highlights the high $\mathrm{PM}_{2.5}$ and $\mathrm{PM}_{10}$ peak values present during the month of February 2020 in all considered cities, with values in excess of $60 \mu \mathrm{g} / \mathrm{m}^{3}$ observed 3 to 9 times for $\mathrm{PM}_{2.5}$ and 3 to 14 times for $\mathrm{PM}_{10}$. This figure also reveals that three major particulate matter pollution outbreak events took place during the month of February 2020: the first one covering the period 06-11 February, the second one covering the period 15-19 February, and the third one covering the period 20-26 February.

In the present research effort, for the purpose of comparing $\mathrm{PM}_{10}$ measurements with epidemiologic parameters, we focused our attention on the $\mathrm{PM}_{10}$ pollution levels observed over the 12-day period from 15 to 26 February 2020, when very high and persistent $\mathrm{PM}_{10}$ concentration values were present over a major portion of the Po Valley.

\subsection{Correlations between epidemiologic parameters and PM concentrations}

The effective impact of $\mathrm{PM}_{2.5}$ and $\mathrm{PM}_{10}$ particles on SARS-CoV-2/COVID-19 infection outbreak is expected to be strongly dependent on particle persistency in the air, i.e., on the duration of the effective exposure to particulate pollution of the human respiratory system throughout the weeks preceding the pandemic onset. In a previous paper by Borro et al. (2020), the variability of the infection rate, the mortality rate, and the case fatality rate as a function of particle concentration was estimated for $\mathrm{PM}_{2.5}$ particles only, recognizing a primary role of these particles in inducing an over-expression of ACE-2 in the human 

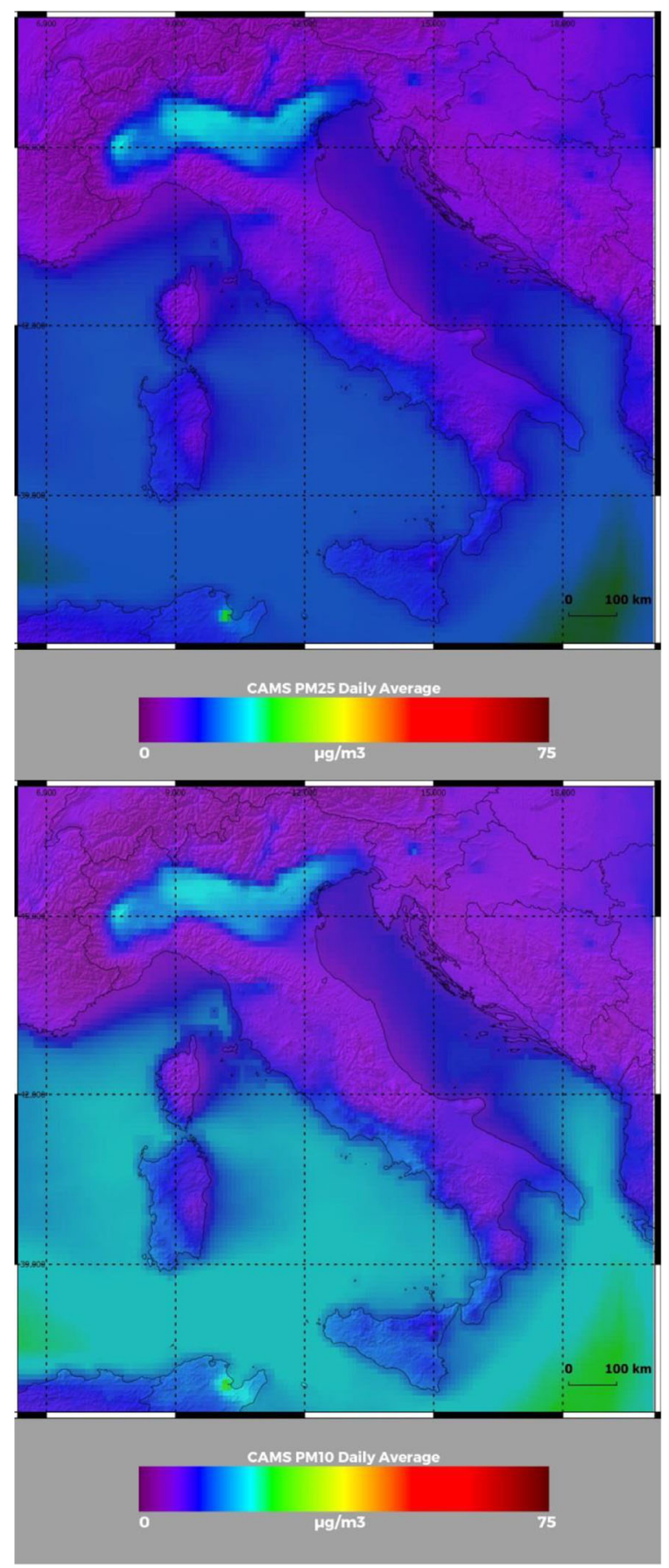

Fig. $3 \mathrm{PM}_{2.5}$ (upper panel) and $\mathrm{PM}_{10}$ (lower panel) concentrations at 00:00 UTC on 29 February 2020 from nearreal-time ECMWF-CAMS analysis over an area encompassing the Italian peninsula and portions of the surrounding nations 
respiratory system (see papers by Gemmati et al. 2020; Devaux et al. 2020; Bunyavanich et al. 2020; Leung et al. 2020). In the present paper, we extend the analysis to $\mathrm{PM}_{10}$ particles, thus assessing the incidence of this additional pollution source on the observed epidemiologic parameters. Specifically, $\mathrm{PM}_{10}$ concentration measurements over the period 15-26 February 2020 are compared with epidemiologic data for all 110 Italian provinces, as reported by the Italian Statistics Institute (ISTAT 2020), over the period 20 February-31 March 2020. The list of all 110 Italian provinces, their population, and their population density is reported in Table 1. Actually, the epidemiologic data report from ISTAT includes only 107 provinces, as in fact four provinces in Southern Sardinia (Carbonia-Iglesias, Ogliastra, Olbia-Tempio, and Medio Campidano) are grouped together as "Sud Sardegna."

Three epidemiologic parameters are considered in this study: the infection rate, or incidence of the pathology, quantifying the pathology appearance frequency in a particular population (Shields and Twycross 2003), which is defined as the number of infected people in a province normalized to the province population; the mortality rate (Gülmezoglu et al. 2004), quantifying the frequency of occurrence of death in a defined population, which is defined as the number of deaths in a province normalized to the province population; and the case fatality rate (Harrington 2020), quantifying the frequency of occurrence of deaths from a specified pathology compared to the total number of people diagnosed with the pathology, which is

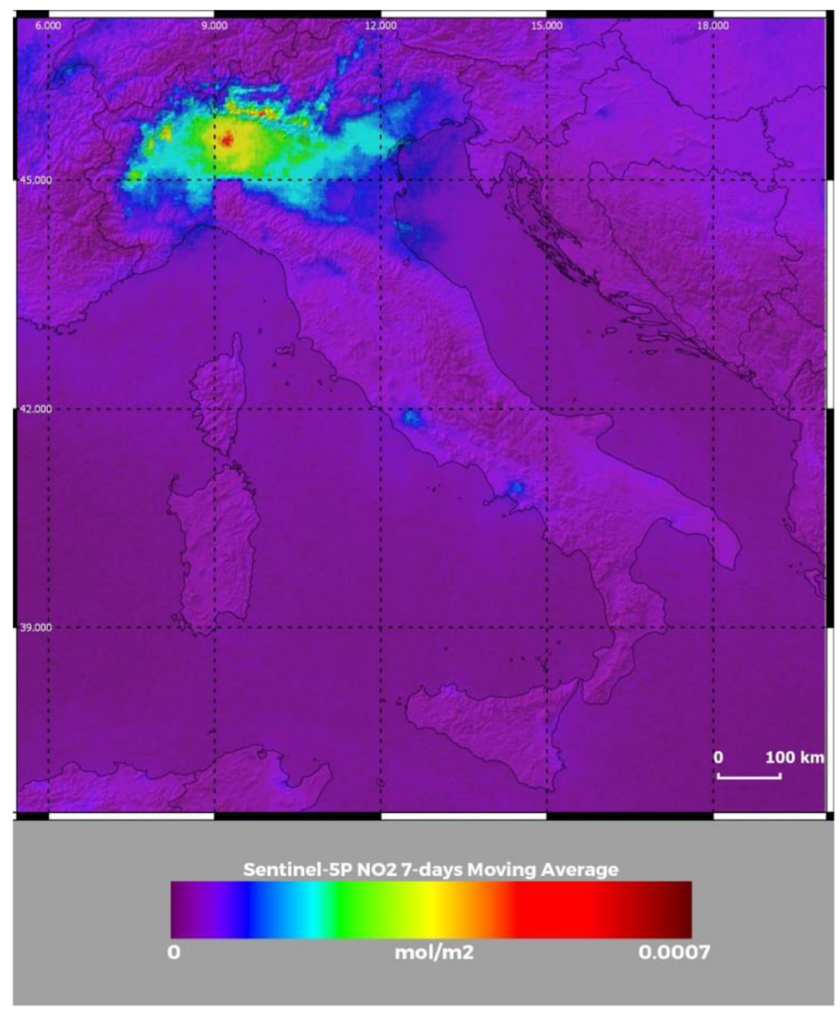

Fig. $4 \mathrm{NO}_{2}$ concentrations at 12:30 UTC on 17 February 2020 from Copernicus Sentinel-5P TROPOMI data over an area encompassing the Italian peninsula and portions of the surrounding nations. Data are obtained as 7day averages centered on the reference day, i.e., on 17 February 2020, thus including the data from 14 to 20 February 2020 


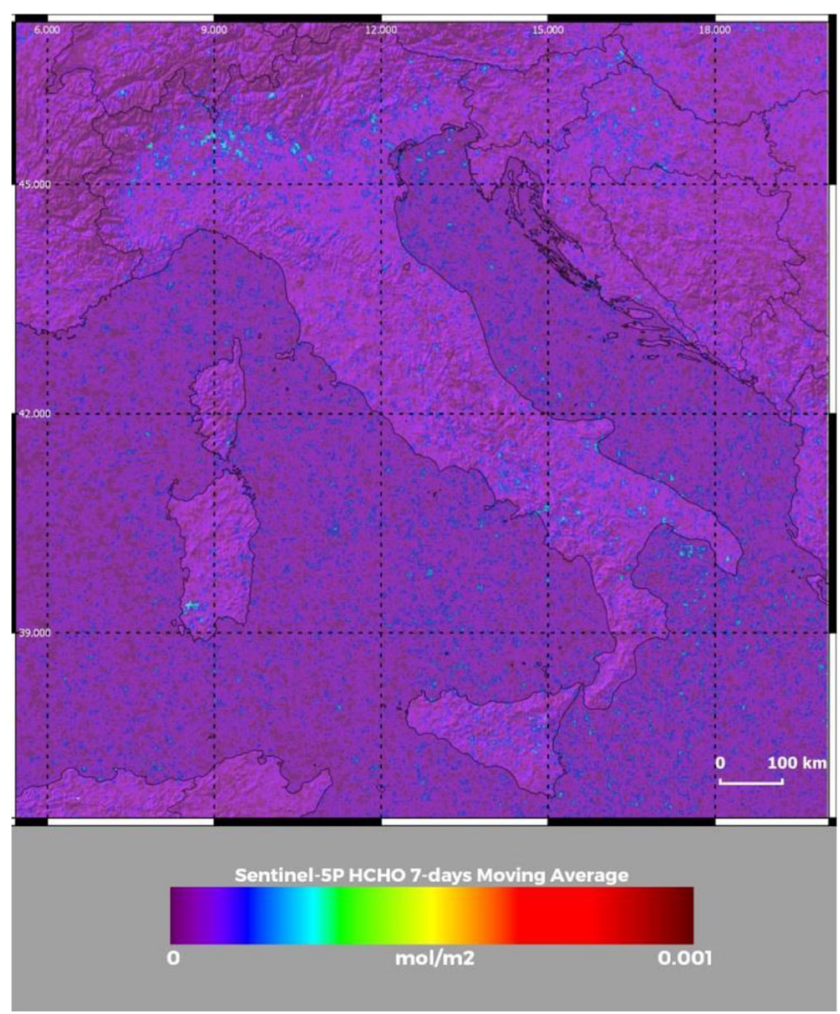

Fig. $5 \mathrm{HCHO}$ (formaldehyde) concentrations at 12:30 UTC on 17 February 2020 from Copernicous Sentinel-5P TROPOMI data over an area encompassing the Italian peninsula and portions of the surrounding nations. Data are obtained as 7-day averages centered on the reference day, i.e., on 17 February 2020, thus including the data from 14 to 20 February 2020

defined as the number of reported deaths in a province normalized to the number of reported cases.

A statistical analysis is carried out to correlate the infection rate, the mortality rate, and the case fatality rate with $\mathrm{PM}_{10}$ concentrations. In the paper by Borro et al. (2020), $\mathrm{PM}_{2.5}$ pollution levels from a single station within each province territory were considered. The present study considers $\mathrm{PM}_{10}$ concentration measurements from all ground stations available within each Province territory, which allows accounting for the natural variability of the particulate matter pollution within the single province territories, including urban, semi-urban, and rural areas. In fact, particulate concentration variability within single province territories is an important aspect to be properly accounted for when correlating epidemiologic parameters with atmospheric pollution. For this purpose, particulate concentration variability within each single province territory is used as a weighting factor in the statistical analysis carried out to correlate epidemiologic parameters with $\mathrm{PM}_{10}$ concentrations. Specifically, we computed the average $\mathrm{PM}_{10}$ concentration value over the period 15-26 February for each station within each province territory. The mean and standard deviation of these time-averaged PM concentration values from the different stations within each province territory are used in the statistical analysis for comparison with the epidemiologic parameters. 


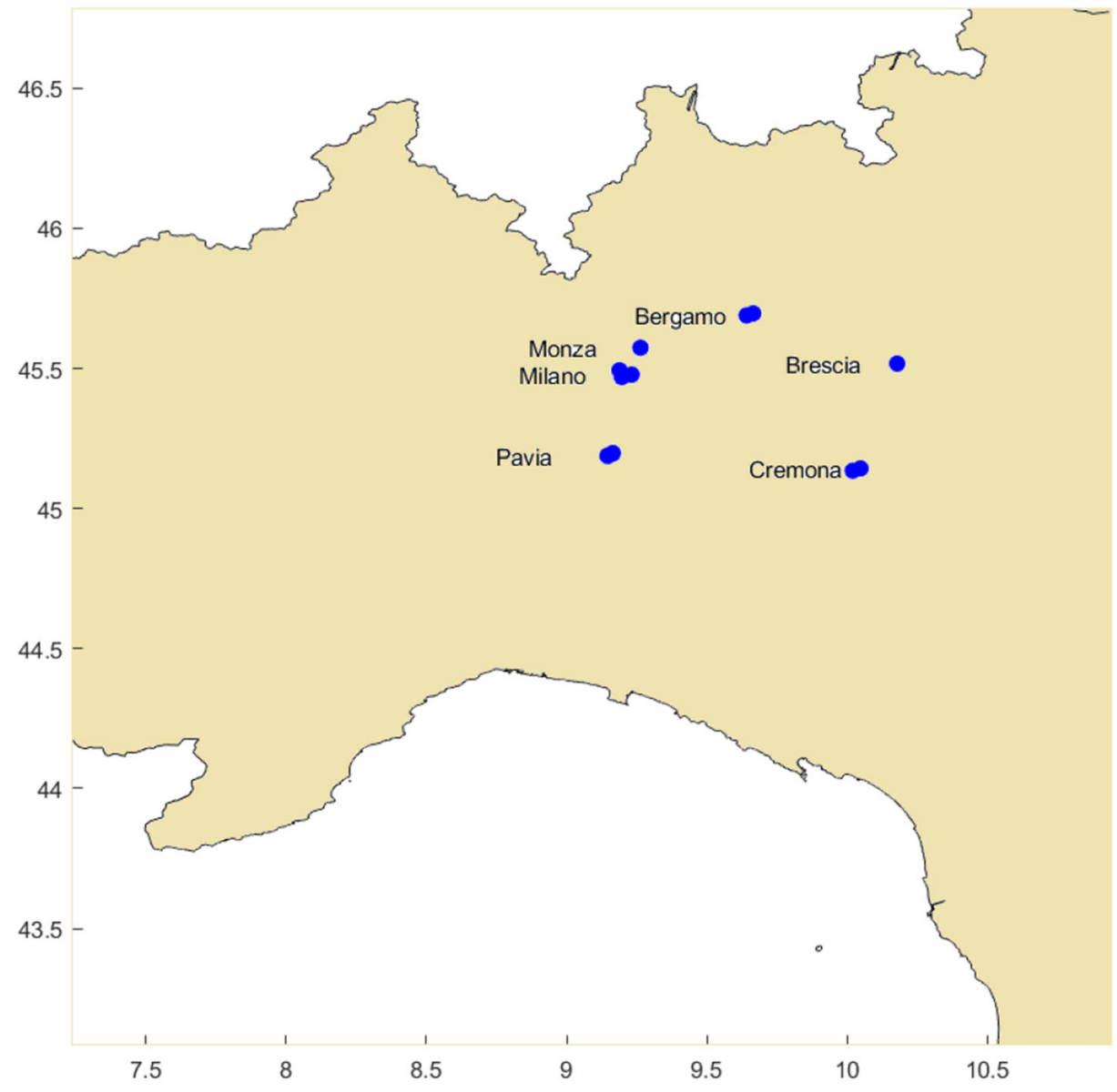

Fig. 6 Locations of the metropolitan cities in Lombardia (Bergamo, Brescia, Cremona, Milano, Monza, and Pavia), whose data are considered in Figs. 6 and 7. The locations of one to three stations are considered for each city

A linear fit was applied to the mean $\mathrm{PM}_{10}$ and $\mathrm{PM}_{2.5}$ concentration values for the 110 Italian provinces over the period 15-26 February 2020, using a linear regression function with the form $Y=A+B \times X$, with $A$ being the mean $\mathrm{PM}_{2.5}$ concentration values and $Y$ the corresponding mean $\mathrm{PM}_{10}$ concentration values, with the weight in the fit given by the error bars $\Delta Y$. The regression analysis yielded the following results: $A=8.1 \pm 0.5 \mu \mathrm{g} / \mathrm{m}^{3}, B=1.04 \pm 0.02$, correlation coefficient $=0.96$ and $p$ value $<0.0001$. These results reveal a very high correlation between mean $\mathrm{PM}_{10}$ and $\mathrm{PM}_{2.5}$ concentration values in most provinces. This result testifies the simultaneous and co-located presence of both particle types, as expected, since $\mathrm{PM}_{2.5}$ particles are, by definition, included within $\mathrm{PM}_{10}$ particles and therefore $\mathrm{PM}_{10}$ concentrations are dependent on $\mathrm{PM}_{2.5}$ concentrations. Specifically, based on the above reported numbers, mean $\mathrm{PM}_{10}$ concentration values are found on average to be higher than corresponding $\mathrm{PM}_{2.5}$ values by $\sim 8 \mu \mathrm{g} / \mathrm{m}^{3}$, with the concentration growth rates being almost identical for $\mathrm{PM}_{2.5}$ and $\mathrm{PM}_{10}$ particles (4\% higher for $\mathrm{PM}_{10}$ particles with respect to $\mathrm{PM}_{2.5}$ ). 

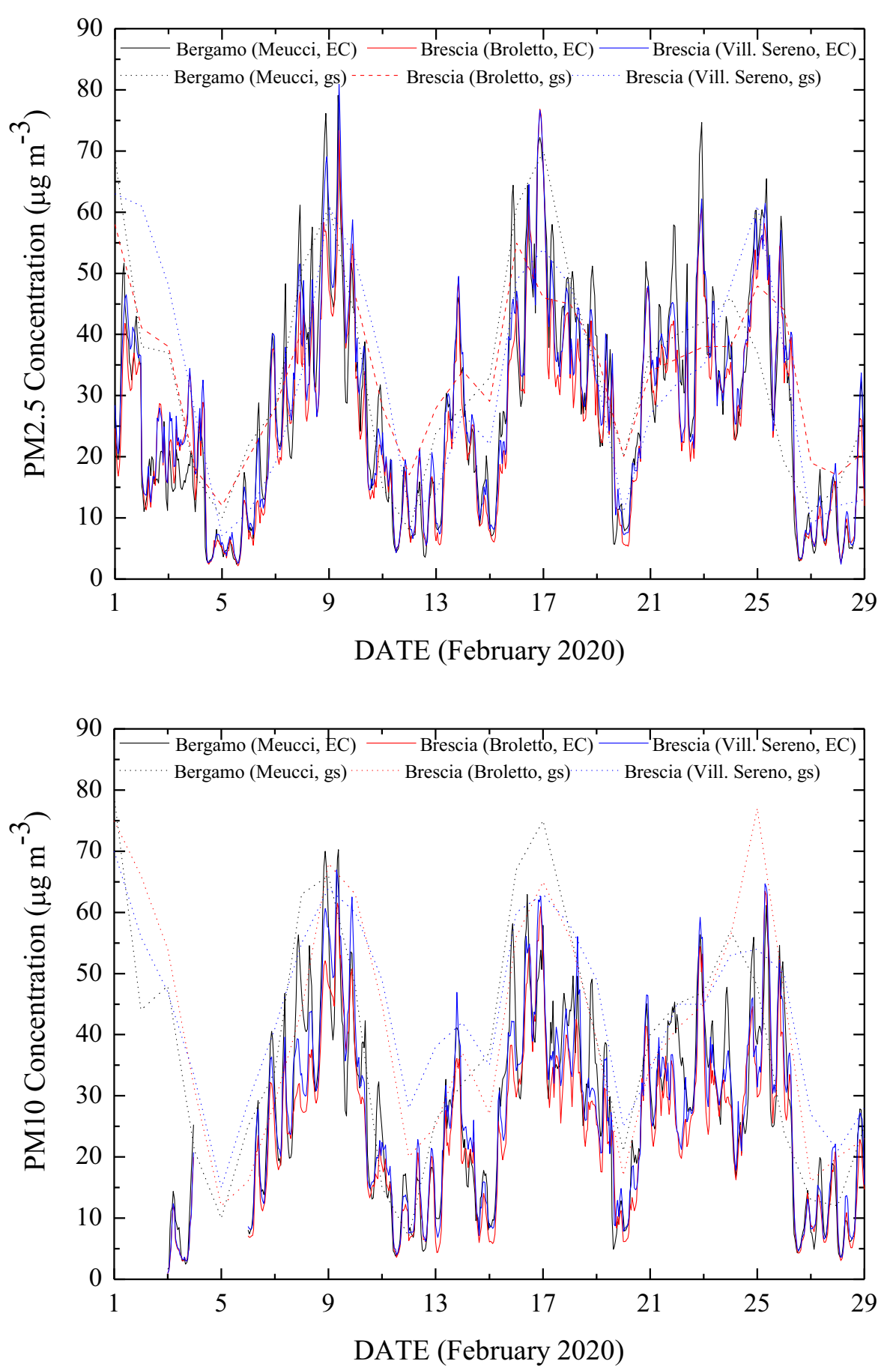

Fig. $7 \mathrm{PM}_{2.5}$ (upper panel) and $\mathrm{PM}_{10}$ (lower panel) concentrations over the month of February 2020 as measured by the three ground stations (gs), one in Bergamo (via Meucci, $45^{\circ} 41^{\prime} 24^{\prime \prime} \mathrm{N}, 09^{\circ} 38^{\prime} 28^{\prime \prime} \mathrm{E}$ ) and two in Brescia

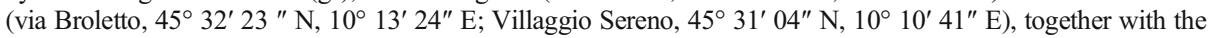
data from near-real-time ECMWF-CAMS analysis (EC) 
Coming to the results from the statistical analysis correlating epidemiologic parameters with $\mathrm{PM}_{10}$ concentrations, the upper panel of Fig. 9 compares the "case fatality rate" in the period 20 February-31 March 2020 with the corresponding average $\mathrm{PM}_{10}$ concentration values in the period 15-26 February 2020 for all 110 Italian provinces. A linear fit was

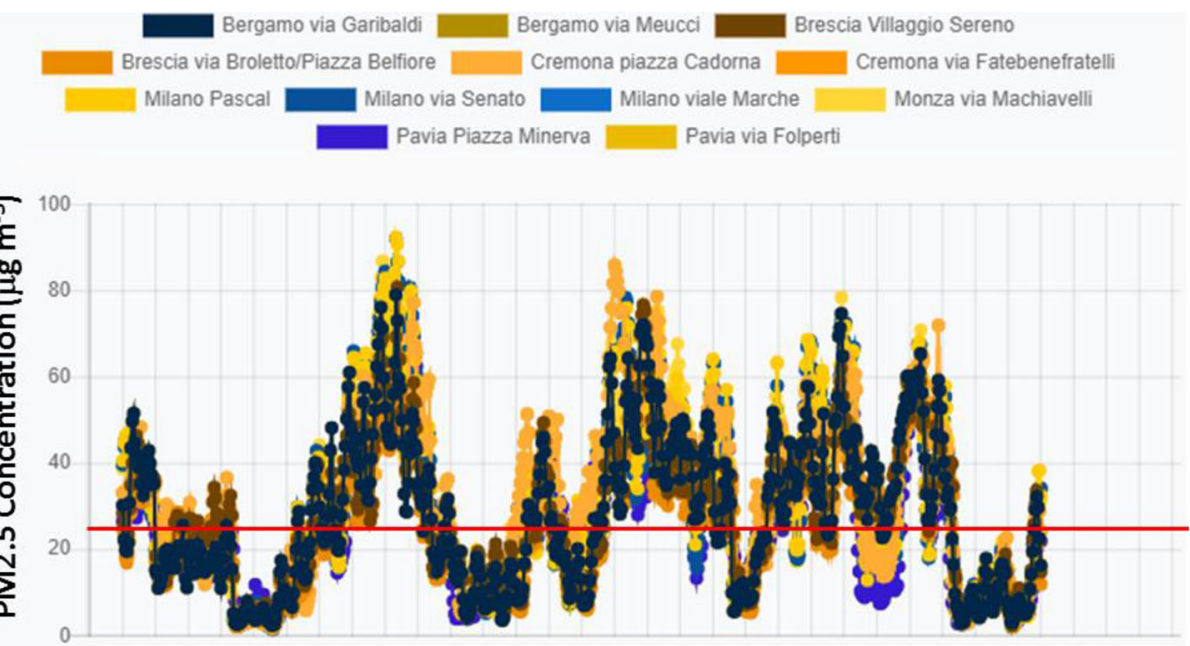

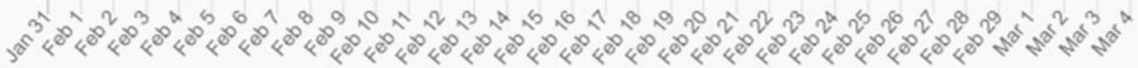

\section{DATE (February 2020)}

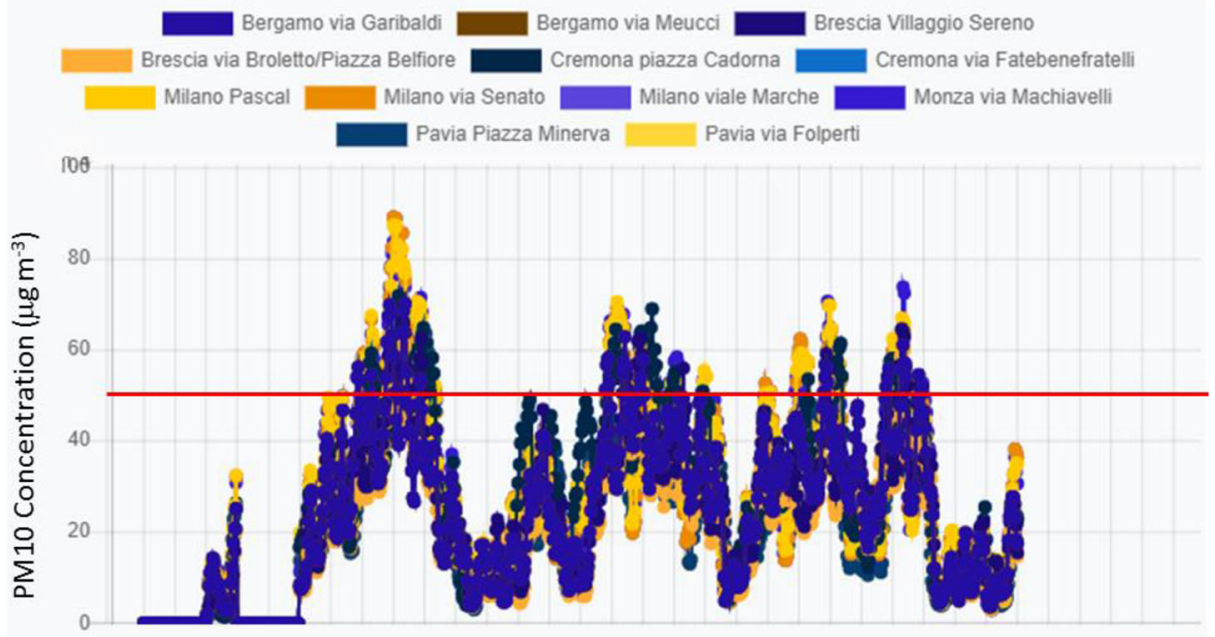

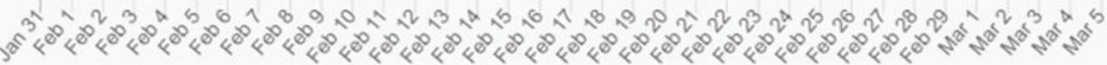

\section{DATE (February 2020)}

Fig. 8 Near-real-time ECMWF-CAMS analysis of $\mathrm{PM}_{2.5}$ (upper panel) and $\mathrm{PM}_{10}$ (lower panel) concentrations over the month of February 2020 for several metropolitan cities in Lombardia (Bergamo, Brescia, Cremona, Milano, Monza, and Pavia). One to three locations are considered for each city 
Table 1 List of all 110 Italian provinces, their population, and their population density. Four provinces in Southern Sardinia (Carbonia-Iglesias, Ogliastra, Olbia-Tempio, and Medio Campidano) are grouped together as "Sud Sardegna"

\begin{tabular}{lllllll}
\hline N. Province & $\begin{array}{l}\text { Population } \\
\text { (inhabitants) }\end{array}$ & $\begin{array}{l}\text { Density } \\
\left(\text { inhab } / \mathrm{km}^{2}\right)\end{array}$ & $N$. & Province & $\begin{array}{l}\text { Population } \\
\text { (inhabitants) }\end{array}$ & $\begin{array}{l}\text { Density } \\
\left(\mathrm{inhab} / \mathrm{km}^{2}\right)\end{array}$ \\
\hline
\end{tabular}

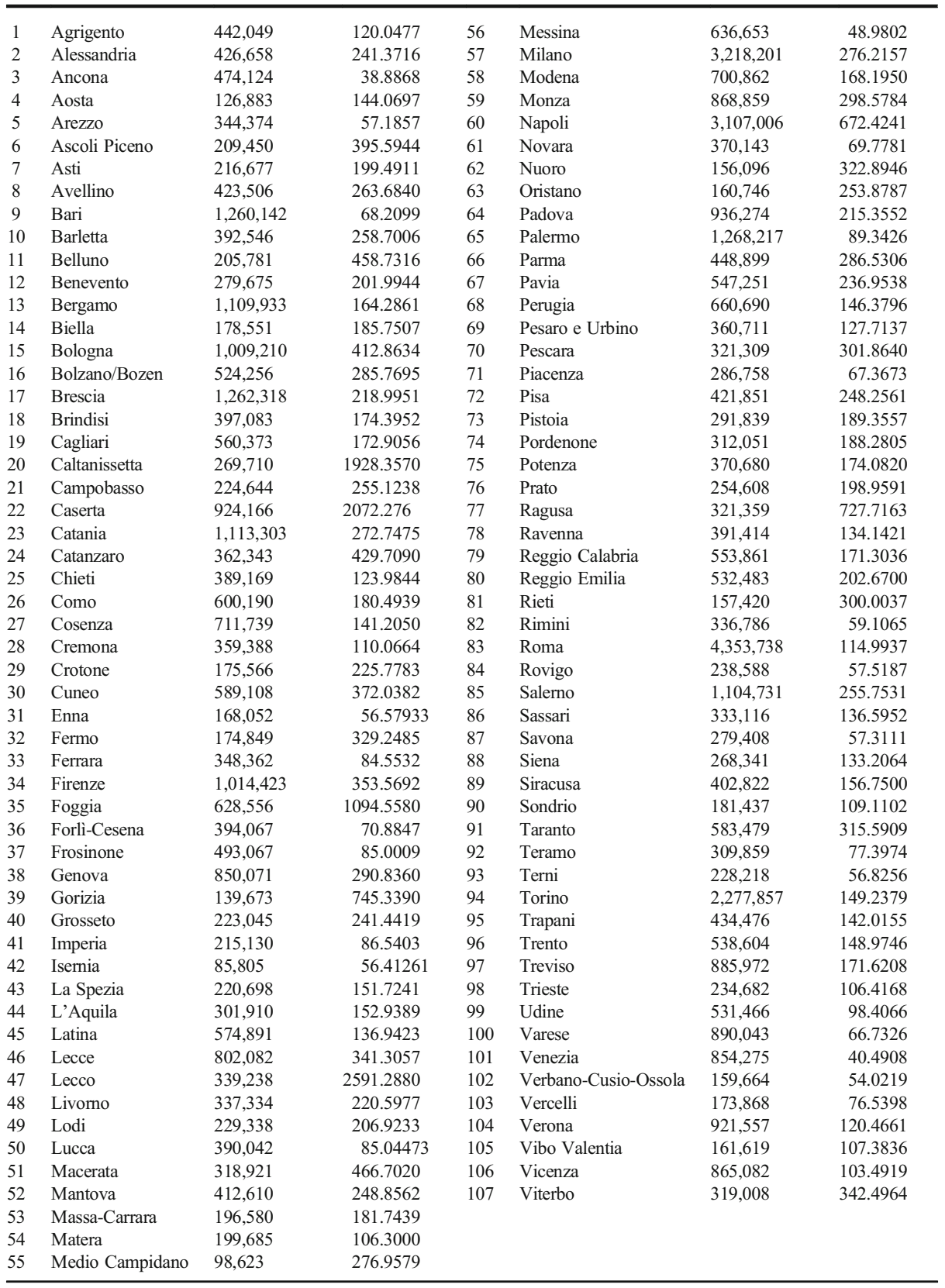


applied to the data, using a linear regression function with the form $Y=A+B \times X$, with $X$ being the average $\mathrm{PM}_{10}$ concentration values and $Y$ the corresponding "case fatality rate" values. Values of $\mathrm{PM}_{10}$ concentration variability within each province territory, i.e., its standard deviation, are included as error bars $\Delta X$ and are used as a weighting factor in the statistical analysis. The following results are obtained: $A=(-0.123 \pm 0.002), B=(6.7 \pm 0.3) \times 10^{-3} \mathrm{~m}^{3} /$ $\mu \mathrm{g}$, with the Pearson's correlation coefficient being equal to 0.89 and the Spearman's correlation coefficient being equal to 0.87 . The $p$ value is smaller than 0.0001 , which indicates less than $0.01 \%$ probability that no statistically significant relationship is present between the two compared quantities. A slope of the regression line of the "case fatality rate" vs. $\mathrm{PM}_{10}$ concentration of $6.7 \times 10^{-3} \mu \mathrm{g} / \mathrm{m}^{3}$ implies a doubling (from 3 to $6 \%$ ) of the mortality rate of infected patients for an average $\mathrm{PM}_{10}$ concentration increase from 22 to $27 \mu \mathrm{g} / \mathrm{m}^{3}$.

The middle panel of Fig. 9 compares the "incidence of the pathology" in the period 20 February-31 March 2020 with the corresponding average $\mathrm{PM}_{10}$ concentration values in the period 15-26 February 2020 for the 110 Italian provinces. The best-fit statistical analysis carried out to correlate these two parameters, with $X$ being the average $\mathrm{PM}_{10}$ concentration values and $Y$ the corresponding "incidence of the pathology" values, indicates a regression line with $A=(-5.6 \pm 0.1) \times 10^{-3}$ and $B=(2.48 \pm 0.06) \times 10^{-4} \mathrm{~m}^{3} / \mu \mathrm{g}$, a Pearson's correlation coefficient equal to 0.82 , a Spearman's correlation coefficient equal to 0.79 , and $p$ value $<0.0001$. A slope of the regression line of the "incidence of the pathology" vs. $\mathrm{PM}_{10}$ concentration of $2.48 \times 10^{-4} \mathrm{~m}^{3} / \mu \mathrm{g}$ implies a doubling (from 1 to $2 \%$ ) of the incidence of the pathology for an average $\mathrm{PM}_{10}$ concentration increase from 25 to $29 \mu \mathrm{g} / \mathrm{m}^{3}$.

The lower panel of Fig. 9 compares the "mortality rate" in the period 20 February-31 March 2020 with the corresponding average $\mathrm{PM}_{10}$ concentration values in the period 15-26 February 2020 for the 110 Italian provinces. The linear regression analysis, with $X$ being the average $\mathrm{PM}_{10}$ concentration values and $Y$ the corresponding "mortality rate" values, leads the following results: $A=(-1.25 \pm 0.03) \times 10^{-3}$ and $B=(5.46 \pm 0.14) \times 10^{-5} \mathrm{~m}^{3} / \mu \mathrm{g}$, a Pearson's correlation coefficient equal to 0.80 , a Spearman's correlation coefficient equal to 0.79 , and $p$ value $<0.0001$. The slope of the regression line of the "mortality rate" vs. $\mathrm{PM}_{10}$ concentration is $(5.46 \pm 0.14) \times 10^{-5} \mathrm{~m}^{3} / \mu \mathrm{g}$, which implies a tripling (from 0.1 to $0.3 \%$ ) of the mortality rate for an average $\mathrm{PM}_{10}$ concentration increase from 25 to $29 \mu \mathrm{g} / \mathrm{m}^{3}$.

The above results reveal the presence of much higher correlation coefficients than those reported in the paper by Borro et al. (2020) ( 0.89 against 0.7 for the "case fatality rate" vs. PM concentrations, 0.80 against 0.65 for the mortality rate vs. PM concentrations, and 0.82 against 0.67 for the incidence of the pathology vs. PM concentrations). The higher values found in the present correlation analyses are to be attributed to several motivations. First, the present correlation analyses are considering $\mathrm{PM}_{10}$ particles instead of $\mathrm{PM}_{2.5}$ particles, the formers acting as a more efficient virus carriers (see section 3.1). Secondly, the present analyses are considering PM concentration values, which properly account for their variability within the single province territories, using this variability as a weighting factor in the regression analysis. This implies that data points characterized by a higher variability of PM concentrations are considered with a lower weight in the best-fit analysis. This approach is quite effective in properly filtering potential biases or outliers associated with the use of a single pollution monitoring station in each province territory, especially in those cases when PM pollution levels sensitively vary within the province territory. Correlation coefficient values in the range $0.80-0.89$ testify a high statistical significance. The correlation coefficient quantifies the strength and direction of the linear relationship between two variable quantities and the reliability of the linear model depends on the number observed data points. Thus, both 

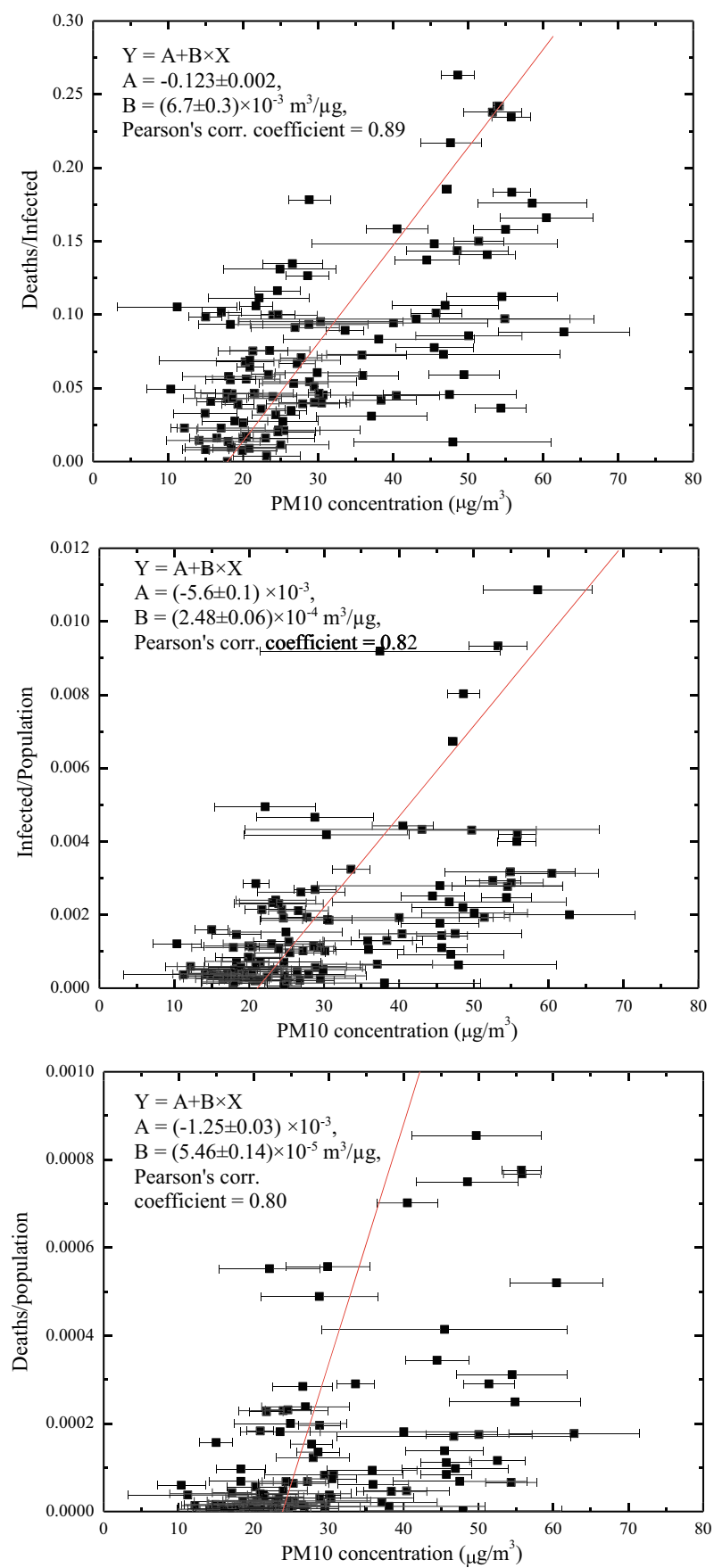

Fig. 9 Linear regression analysis correlating the case fatality rate (upper panel), the incidence of the pathology (middle panel), and the mortality rate (lower panel) in the period 20 February-31 March 2020 with the average $\mathrm{PM}_{10}$ concentration values in the period 15-26 February 2020. The statistical analysis is extended over all 110 Italian provinces. Error bars represent the standard deviations of the PM concentration values in the different stations within each province territory 
the correlation coefficient value and the number of considered data points need to be properly accounted for in the assessment of the significance of the results. In general, the larger is the number data points, the lower is the acceptable correlation coefficient.

Based on the above analyses' results, it appears clear that the most effective epidemiological parameter to assess the impact of particulate pollution on COVID-19 pandemic is the case fatality rate. In fact, results from the analysis reveal that case fatality rate is the epidemiologic parameter characterized by the highest correlation with $\mathrm{PM}_{10}$ concentrations, and consequently is the epidemiologic parameter most affected by particulate pollution. This is also coherent with the possible interpretation of the results in terms of biological response of the human respiratory system to particulate pollution exposition. In this regard it should be noted that, during the second pandemic wave in Autumn 2020, the number of infected people has strongly increased over the entire Italian territory, also as a result of the increased number and higher distribution of virus hotbeds, with the geographical distribution of infected patients becoming almost evenly distributed over the Italian territory. However, what has remained substantially unchanged with respect to the first pandemic wave is the case fatality rate, with strongly unbalanced values between high and low polluted areas.

Correlations between the different epidemiologic parameters and PM concentrations are strongly dependent on the elapsed time lag considered between the pollution events and the time window considered for epidemiologic parameters, as well as on the duration of the time window considered for the pollution event. In general, the consideration of the presence of a possible time gap between population exposure to enhanced PM concentrations and the onset of the infection, and the eventual death of patients, ensures that the pollution exposition period is long enough to induce a biological response in human tissues. A sensitivity study was carried out considering different time gaps and pollution integration times. Unfortunately, in the sensitivity analysis, there was no possibility to also vary the time window considered for the assessment of the epidemiologic parameters, as in fact values for these parameters were provided by the Italian Statistics Institute only for the period 20 February-31 March 2020 (ISTAT 2020). Specifically, we considered three different time windows for particulate pollution: 01-26 February 2020, 01-19 February 2020, and 15-26 February 2020. The first time window allows including all three major pollution outbreaks in February 2020 identified in Figs. 6 and 7, i.e., the periods 06-11 February, 15-19 February, and 20-26 February. The second time window includes only the first two pollution outbreak events, while the third time window includes the last two pollution outbreak events. Results reported in Table 2, which focus specifically on the "case fatality rate", reveal a maximum correlation when comparing the epidemiologic parameters in the period 20 February-31 March 2020 vs. the corresponding average PM concentration values observed in the period 15-26 February 2020. The table also lists the values of the time intervals elapsed from infection to death, which are computed from the central day of the considered pollution time window and the central day of the time interval considered for the epidemiologic parameter (20 February-31 March 2020). Maximum correlation is observed for an elapsed time of 20 days.

The revealed positive correlation between epidemiologic parameters and $\mathrm{PM}_{10}$ concentrations identified in the present research effort does not imply a direct and univocal cause-effect relation, but it indicates that PM pollution is certainly one of the several factors that influenced the pandemic outbreak in Northern Italy in the period February-March 2020. In principle, some other circumstance (for example, the effect of meteorological variables) could have caused both epidemiologic factors and $\mathrm{PM}_{10}$ concentrations to change. With regard to this aspect, the reader should be aware that the reported correlation is to be interpreted in a 
mathematical sense, i.e., it testifies a co-occurrence of low/high values of COVID-19 epidemiologic parameters and low/high pollution levels.

The possible occurrence of spurious correlations has to be carefully accounted for (Bolton 1994). In statistics, a spurious correlation refers to a connection between two variables which may be caused by a third factor that may be not apparent at the time of analysis, sometimes called a confounding factor. There are numerous approaches to spot spurious correlations. Among others: ensuring a proper representative sample, obtaining an adequate sample size, being wary of arbitrary endpoints, using a null hypothesis and checking for a low $p$ value. In the present statistical analysis, the availability of a representative data sample is ensured, as in fact the considered epidemiologic parameters' data and PM measurements are considered for the entire Italian territory and population and not only for a subset of these. For most statistical applications, the sample size is considered adequate when exceeding 100 elements (Francis et al. 2010; Sandelowski, 1995; Malterud et al. 2016). The endpoints in our study are the considered epidemiologic parameters, i.e., the case fatality rate and the infection and mortality rates, which are well-established clinical events or outcomes that can be objectively measured (Pilz et al. 2012). $p$ values smaller than 0.0001 where found in all statistical analyses correlating epidemiologic parameters with $\mathrm{PM}_{10}$ concentrations. The above arguments testify that in our analysis, the occurrence of spurious correlation is very unlikely.

The effect of population density on epidemiologic parameters has also been investigated. Results indicate that this effect is quantitatively far less important than PM pollution. Specifically, Fig. 10 shows the linear regression analysis correlating population density with the incidence of the pathology (upper panel), the mortality rate (middle panel), and the case fatality rate (lower panel) in the period 20 February-31 March 2020. This analysis is again extended over all 110 Italian provinces. Specifically, the statistical analysis correlating the incidence of the pathology with population density reveals a totally missing correlation, with a Pearson's correlation coefficient of 0.045 and a Spearman's correlation coefficient of 0.17 (Fig. 10, upper panel). The $p$ value is equal to 0.65 , which indicates $65 \%$ probability that no statistically significant relationship is present between the two compared quantities. The statistical analysis correlating the mortality rate with population density reveals a very low correlation, with a Pearson's correlation coefficient of 0.19 , a Spearman's correlation coefficient of 0.24 , and a $p$ value equal to 0.051 (Fig. 10, middle panel). Finally, the analysis correlating the case fatality rate with population density reveals an almost totally missing correlation, with a Pearson's correlation coefficient of 0.093 , a Spearman's correlation coefficient of 0.18 , and a $p$ value equal to 0.34 (Fig. 10, lower panel). The above results indicate that correlations between epidemiologic parameters and population density are not significant.

Table 2 Results for the regression analysis, expressed in terms of Pearson's correlation coefficient, considering different elapsed time lags between the pollution events and the time interval considered for the "case fatality rate." The table also lists the times elapsed from infection to death, which are computed from the central day of the considered pollution time window and the central day of the time interval considered for the "case fatality rate" (20 February-31 March 2020)

Particulate pollution time window Pearson's correlation coefficient Time elapsed since infection (days)

$1 \quad 01-26$ February $2020 \quad 0.72 \quad 27$

$201-19$ February $2020 \quad 0.70 \quad 31$

$3 \quad 15-26$ February $2020 \quad 0.89 \quad 20$ 
The reported statistical results do not completely exclude a correlation between the abovementioned epidemiologic parameters and population density: they only underline that there are so many outliers in the analysis to make this correlation meaningless. More specifically, the different panels of Fig. 10 reveal the presence of data points with a highly scattered distribution. This implies that outliers are present in the analysis, i.e., there is a number of provinces with low population density and high values of the epidemiologic parameters and a number of provinces with high population density and low values of the epidemiologic parameters, and the presence of these data points is severely compromising the regression analysis. For example, provinces such as Napoli, Monza, and Trieste are characterized by quite high population densities, but have low values for the epidemiologic parameters and were only slightly affected by COVID-19. Analogously, provinces such as Cremona, Lodi, and Piacenza are characterized by low population densities, but were severely affected by COVID-19. Obviously, few outliers were also present in the statistical analysis correlating the epidemiologic parameters with $\mathrm{PM}_{10}$ concentrations (for example, the province of Aosta in Valle d'Aosta, where a large number of hospitalizations refer to patients coming from other areas of the Italian territory as a result of their short-term mobility associated with winter skiing holidays). However, these outliers were very few and their presence only slightly affected the results of the regression analysis.

\section{Summary and final remarks}

The devastating impact in terms of number of infected people and deaths associated with the first wave of the COVID-19 pandemic in the early portion of 2020 was the result of a variety of contributing causes and circumstances. While the spread and effective impact of the SARS$\mathrm{CoV}-2$ virus in Northern Italy was primarily related to the lifestyles and social habits of the different communities and the presence of specific infection hotbeds triggered by individual infected patiens often returning from travels abroad, environmental and meteorological factors have possibly also played a role.

In the present paper, we illustrated the evolution of $\mathrm{PM}_{2.5}$ and $\mathrm{PM}_{10}$ concentrations in Northern Italy throughout the month of February 2020, identifying in the central part of the month the presence of enhanced $\mathrm{PM}_{2.5}$ and $\mathrm{PM}_{10}$ concentrations over large portions of the Po Valley, with levels exceeding $60 \mu \mathrm{g} / \mathrm{m}^{3}$ for both species. A marked reduction of pollution levels was observed in the final part of the month, few days after the shutdown of all vehicular and industrial activities associated with the lockdown in Northern Italy started on 25 February 2020, with $\mathrm{PM}_{2.5}$ and $\mathrm{PM}_{10}$ concentrations abruptly dropped to levels not exceeding 15-20 $\mathrm{\mu g}$ / $\mathrm{m}^{3}$ for both species.

Computations were carried out using an analytical microphysical model capable to simulate the different coagulation processes (Brownian diffusion, laminar shear, turbulent fluctuations, uniform horizontal motion, and gravitational and drag forces) occurring during the formation of virus-transmitting PM particles. The simulation model uses as input data $\mathrm{PM}_{2.5}$ and $\mathrm{PM}_{10}$ pollution measurements and specific literature information on exhaled particles' sizes and concentrations, their residence time, transported viral dose, and minimum infective dose. Model results allow to affirm that airborne transmission through virus-laden PM particles, and its capability to convey SARS-CoV-2 into the human respiratory system, may have played an important role in the early 2020 pandemic outbreak of COVID-19 infection in Northern Italy. This statement is supported by the model results illustrated in Section 4, which clearly 

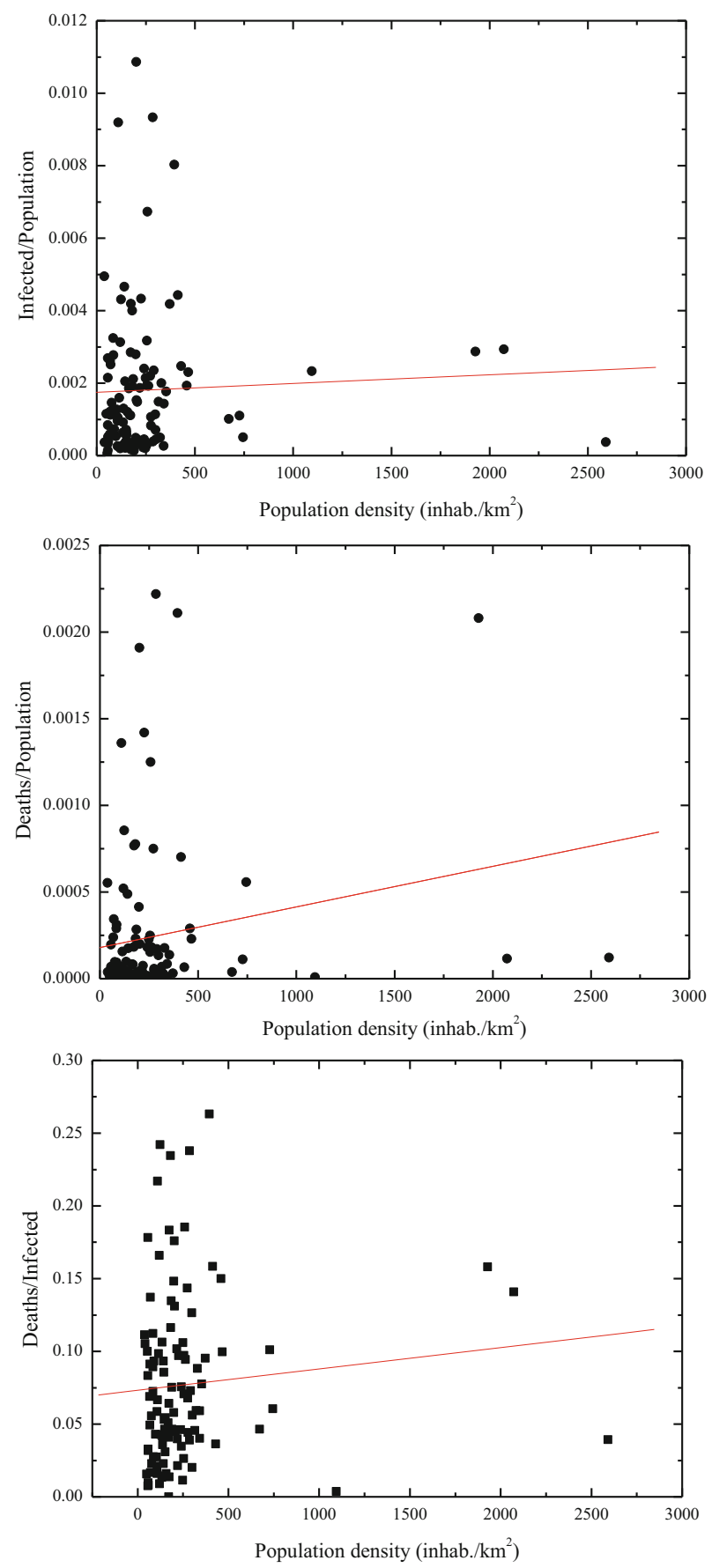

Fig. 10 Linear regression analysis correlating the case fatality rate (upper panel), the incidence of the pathology (middle panel), and the mortality rate (lower panel) in the period 20 February-31 March 2020 with the population density. The statistical analysis is extended over all 110 Italian provinces 
indicate that the number of small breathing and coughing particles coalescing on $\mathrm{PM}_{2.5}$ or $\mathrm{PM}_{10}$ particles may exceed the minimum infective dose of SARS-CoV-2 and other respiratory viruses.

While airborne transmission through virus-laden PM particles is a possible mechanism to convey viable amounts of SARS-CoV-2 into the human respiratory system, which is likely to happen in high PM pollution conditions, the more traditional airborne transmission directly through the inalation of infectious briefing and coughing particles exhaled by symptomatic and or asymptomatic patients, especially in case of prolonged permanence in indoor unventilated spaces, is a very likely process to take place (Morawska and Cao 2020), especially if the preliminary emerging research results on the high viral load and infertility of SARS-COV-2 will be confirmed. A deeper insight into these mechanisms should be the object of future dedicated research efforts.

In the paper, we have also reported the results from a statistical analysis correlating the infection rate, or incidence of the pathology, the mortality rate, and the case fatality rate with PM concentrations, which reveals a high correlation of these epidemiologic parameters with $\mathrm{PM}_{10}$ concentrations (correlation coefficients in the range $0.80-0.89$ ), with the case fatality rate doubling (from 3 to $6 \%$ ) for an average $\mathrm{PM}_{10}$ concentration increase from 22 to $27 \mu \mathrm{g} / \mathrm{m}^{3}$ and the infection rate doubling (from 1 to $2 \%$ ) and the mortality rate a tripling (from 0.1 to $0.3 \%$ ) for average $\mathrm{PM}_{10}$ concentration increase from 25 to $29 \mu \mathrm{g} / \mathrm{m}^{3}$. Epidemiologic parameters' data were also compared with population density data, but no clear evidence of a mutual correlation between these quantities was found.

Correlations between epidemiologic factors and PM concentrations do not imply a direct and univocal cause-effect relationship between PM pollution and the onset of COVID-19 pandemic. The reported correlation has to be interpreted in a mathematical sense, i.e., it testifies the simultaneous co-occurrence of low/high values of both COVID-19 epidemiologic parameters and pollution levels. In the interpretation of the meaning of the high Pearson's and Spearman's correlation coefficient values obtained in the present study, the possible occurrence of spurious correlations due to indirect causes or remote mechanisms has to be carefully accounted for (Bolton 1994). Nevertheless, results from this paper clearly testify that PM pollution is one of the several factors, certainly not a secondary one, which affects COVID-19 incidence. In order for PM pollution to play a role, a number of virus hotbeds need to distributed over the territory. For example, $\mathrm{PM}_{10}$ concentrations in excess of $100 \mu \mathrm{g} / \mathrm{m}^{3}$ were reported in late 2019/early 2020 in several metropolitan cities in China (Beijing, Nanjing, Shanghai, Tianjin, Guangzhou). However, none of these metropolitan cities was affected by a COVID-19 pandemic outbreak and spread similar to the one which exploded in Wuhan (Hebei Region, China) in late 2019, possibly because of the missing presence and concurrence of specific virus hotbeds.

A more quantitative assessment of the contributing role of PM pollution on early 2020 COVID-19 outbreak in Northern Italy implies further dedicated studies, possibly using additional experimental data, with statistics representing one of the several needed tools to be used in the investigation. The experimental/modelling evidence reported in this paper certainly calls for additional research aimed at quantitativly assessing all possible contributing causes based on dedicated sensitivity analyses. Particularly interesting in this regard is the dataset presently under collection during the second pandemic wave in Italy and future research work will focus on identifying possible correlations between the epidemiologic parameters and particulate matter pollution levels for this forthcoming dataset. 
Acknowledgments I wish to strongly acknowledge Dr. Stefano Natali and MEEO S.r.l. for the provision of ECMWF-CAMS analysis data and its graphical display through the ADAM platform (https://adamplatform.eu).

Funding Open access funding provided by Università degli Studi della Basilicata within the CRUI-CARE Agreement. This work was possible based on the support from the Italian Ministry for Education, University and Research under the Grant OT4CLIMA.

\section{Compliance with ethical standards}

Conflict of interest The author declares that he has no conflict of interest.

Open Access This article is licensed under a Creative Commons Attribution 4.0 International License, which permits use, sharing, adaptation, distribution and reproduction in any medium or format, as long as you give appropriate credit to the original author(s) and the source, provide a link to the Creative Commons licence, and indicate if changes were made. The images or other third party material in this article are included in the article's Creative Commons licence, unless indicated otherwise in a credit line to the material. If material is not included in the article's Creative Commons licence and your intended use is not permitted by statutory regulation or exceeds the permitted use, you will need to obtain permission directly from the copyright holder. To view a copy of this licence, visit http://creativecommons.org/licenses/by/4.0/.

\section{References}

Ackerman B (1967) The nature of the meteorological fluctuations in clouds. J Appl Meteorol 6:61-71. https:// doi.org/10.1175/1520-0450(1967)006<0061:TNOTMF>2.0.CO;2

Allen AG, Nemitz E, Shi JP, Harrison RM, Greenwood JC (2001) Size distributions of trace metals in atmospheric aerosols in the United Kingdom. Atmos Environ 35:4581-4591

Appert J, Raynor PC, Abin M, Chander Y, Guarino H, Goyal SM, Zuo Z, Ge S, Kuehn TH (2012) Influence of suspending liquid, impactor type, and substrate on size-selective sampling of MS2 and adenovirus aerosols. Aerosol Sci Technol 46:249-257

ARPA - Agenzia Regionale per la Protezione dell'Ambiente della Lombardia (2017) Settore Monitoraggi Ambientali, Centro Regionale Monitoraggio Qualità dell'aria, Lombardia, Relazione di Monitoraggio Triennale del Piano Regionale degli Interventi per la qualità dell'aria (PRIA), pp 1-285

Asadi S, Bouvier N, Wexler AS, Ristenpart WD (2020) The coronavirus pandemic and aerosols: does COVID19 transmit via expiratory particles? Aerosol Sci Technol 54:635-638

Baron PA, Willeke K (eds) (2001) Aerosol measurement: Principles, techniques, and applications, second edition. John Wiley and Sons, Inc., New York, 61-82

Barr GD (2020) A model showing the relative risk of viral aerosol infection from breathing and the benefit of wearing masks in different settings with implications for Covid-19. MedRxiv:2020.04.28.20082990. https:// doi.org/10.1101/2020.04.28.20082990

Basu S (2020) Computational characterization of inhaled droplet transport in the upper airway leading to SARSCoV-2 infection. medRxiv:2020.07.27.20162362. https://doi.org/10.1101/2020.07.27.20162362

Bolton S (1994) Pharmaceutical statistics, practical and clinical applications, 3rd edn. Marcel Dekker, New York, p 252

Borro M, Di Girolamo P, Gentile G, De Luca O, Preissner R, Marcolongo A, Ferracuti S, Simmaco M (2020) Evidence-based considerations exploring relations between SARS-CoV-2 pandemic and air pollution: involvement of PM2.5-mediated up-regulation of the viral receptor ACE-2. Int J Environ Res Pub1 Health 17:5573. https://doi.org/10.3390/ijerph17155573

Bourouiba L (2020) Turbulent gas clouds and respiratory pathogen emissions: potential implications for reducing transmission of COVID-19. JAMA. 323(18):1837-1838

Brunekreef B (1997) Air pollution and life expectancy: is there a relation? J Occup Environ Med 54:781-784

Bunyavanich S, Do A, Vicencio A (2020) Nasal gene expression of angiotensin-converting enzyme 2 in children and adults. JAMA. 323(23):2427-2429. https://doi.org/10.1001/jama.2020.8707

Carroll RG (2007) 10 - Pulmonary System. In: Carroll RG (ed) Elsevier's Integrated Physiology. Mosby, pp 99115, ISBN 9780323043182. https://doi.org/10.1016/B978-0-323-04318-2.50016-9

Carter WP (1994) Development of ozone reactivity scales for volatile organic compounds. Air Waste 44:881899. https://doi.org/10.1080/1073161X.1994.10467290 
Cui Y, Zhang Z-F, Froines JR, Zhao J, Wang H, Yu S-Z, Detels R (2003) Air pollution and case fatality of SARS in the People's Republic of China: an ecologic study. Environ Health 2:15

De Carlo PF (2004) Particle morphology and density characterization by combined mobility and aerodynamic diameter measurements. Part 1: theory. Aerosol Sci Technol 38(12):1185-1205

Devaux CA, Rolain JM, Raoult D (2020) ACE2 receptor polymorphism: susceptibility to SARS-CoV-2, hypertension, multi-organ failure, and COVID-19 disease outcome. J Microbiol Immunol Infect 53(3):425-435

Dockery DW, Pope CA, Xu X, Spengler JD, Ware JH, Fay ME, Ferris BG, Speizer FE (1993) An association between air pollution and mortality in six U.S. cities. N Engl J Med 329:1753-1759

Duguid JF (1946) The size and the duration of air-carriage of respiratory droplets and droplet-nuclei. J Hyg 4: $471-480$

Evans M (2020) Avoiding COVID-19: aerosol guidelines. MedRxiv. https://doi.org/10.1101/2020.05.21.20108894

Fabian P, McDevitt JJ, DeHaan WH, Fung ROP, Cowling BJ, Chan KH, Leung GM, Milton DK (2008) Influenza virus in human exhaled breath: an observational study. PLoS One 3:e2691. https://doi.org/10. 1371/journal.pone.0002691

Fabian P, Brain J, Houseman EA, Gern J, Milton DK (2011) Origin of exhaled breath particles from healthy and human rhinovirus-infected subjects. J Aerosol Med Pulm Drug Deliv 24(3):137-147. https://doi.org/10. 1089/jamp.2010.0815

Fairchild CI, Stampfer JF (1987) Particle concentration in exhaled breath. Am Ind Hyg Assoc J 48(11):948-949

Fernstrom A, Goldblatt M (2013) Aerobiology and its role in the transmission of infectious diseases. J Pathog. 2013:493960. https://doi.org/10.1155/2013/493960

Findheisen W (1939) Zur Frage der Regentropfenbildung in relnem Wasserwolken. Meteor Z 56:365-368

Francis JJ, Johnston M, Robertson C, Glidewell L, Entwistle V, Eccles MP, Grimshaw JM (2010 Dec) What is an adequate sample size? Operationalising data saturation for theory-based interview studies. Psychol Health 25(10):1229-1245. https://doi.org/10.1080/08870440903194015

Friedlander SK (1977) Smoke, dust and haze - fundamentals of aerosol behavior. Wiley-Interscience, New York

Gemmati D, Bramanti B, Serino ML, Secchiero P, Zauli G, Tisato V (2020) COVID-19 and individual genetic susceptibility/receptivity: role of ACE1/ACE2 genes, immunity, inflammation and coagulation. Might the double X-chromosome in females be protective against SARS-CoV-2 compared to the single Xchromosome in males? Int J Mol Sci 21(10):E3474

Gralton J, Tovey E, McLaws ML, Rawlinson WD (2011) The role of particle size in aerosolised pathogen transmission: a review. J Inf Secur 62(1):1-13. https://doi.org/10.1016/j.jinf.2010.11.010

Guan W, Ni Z, Hu Y, Liang W, Ou C, He J, Liu L, Shan H, Lei CL, Hui DSC, du B, Li LJ, Zeng G, Yuen KY, Chen RC, Tang CL, Wang T, Chen PY, Xiang J, Li SY, Wang JL, Liang ZJ, Peng YX, Wei L, Liu Y, Hu YH, Peng P, Wang JM, Liu JY, Chen Z, Li G, Zheng ZJ, Qiu SQ, Luo J, Ye CJ, Zhu SY, Zhong NS, China Medical Treatment Expert Group for Covid-19 (2020) Clinical characteristics of coronavirus disease 2019 in China. N Engl J Med 382:1708-1720. https://doi.org/10.1056/NEJMoa2002032

Guerra SA, Olsen SR, Anderson JJ (2014 Mar) Evaluation of the SO2 and NOx offset ratio method to account for secondary PM2.5 formation. J Air Waste Manag Assoc 64(3):265-271. https://doi.org/10.1080/ 10962247.2013 .852636

Gülmezoglu AM, Say L, Betrán AP, Villar J, Piaggio G (2004) WHO systematic review of maternal mortality and morbidity: methodological issues and challenges. BMC Med Res Methodol. 05(4):16

Harrington RA (2020) Case fatality rate. Encyclopædia Britannica website. https://www.britannica.com/science/ case-fatality-rate. Last Accessed June $12^{\text {th }}, 2020$

Harrison RM, Tilling R, Callen Romero MS, Harrad S, Jarvis K (2003) A study of trace metals and polycyclic aromatic hydrocarbons in the roadside environment. Atmos Environ 37:2391-2402

He S, Han J (2020) Electrostatic fine particles emitted from laser printers as potential vectors for airborne transmission of COVID-19. Environ Chem Lett. https://doi.org/10.1007/s10311-020-01069-8

Henning S, Ziese M, Kiselev A, Saathoff H, Möhler O, Mentel TF, Buchholz A, Spindler C, Michaud V, Monier M, Sellegri K, Stratmann F (2012) Hygroscopic growth and droplet activation of soot particles: uncoated, succinic or sulfuric acid coated. Atmos Chem Phys 12:4525-4537. https://doi.org/10.5194/acp-12-4525-2012

Hoek B, Brunekreef G, Goldbohm S, Fischer P, van den Brandt PA (2002) Association between mortality and indicators of traffic-related air pollution in the Netherlands: a cohort study. Lancet 360:1203-1209

Hsu JY, Stone RA, Logan-Sinclair RB, Worsdell M, Busst CM, Chung KF (1994) Coughing frequency in patients with persistent cough: assessment using a 24 hour ambulatory recorder. Eur Respir J 7(7):12461253. https://doi.org/10.1183/09031936.94.07071246

ISTAT (2020) Impatto dell'epidemia Covid-19 sulla Mortalità Totale della Popolazione Residente - Primo Trimestre 2020, Ufficio Stampa ISTAT \& Ufficio Stampa ISS, 4 Maggio 2020

Karimzadeh S, Bhopal R, Nguyen Tien H (2020) Review of infective dose, routes of transmission, and outcome of COVID-19 caused by the SARS-CoV-2 virus: Comparison with other respiratory viruses. Preprints 2020: 2020070613. https://doi.org/10.20944/preprints202007.0613.v3 
Khain AP, Pinsky MB (1995) Drop inertia and its contribution to turbulent coalescence in convective clouds. Part I: drop fall in the flow with random horizontal velocity. J Atmos Sci 52:196-206. https://doi.org/10.1175/ 1520-0469(1995)052<0196:DIAICT>2.0.CO;2

Kim H, Zhang Q, Heo J (2018) Influence of intense secondary aerosol formation and long-range transport on aerosol chemistry and properties in the Seoul Metropolitan Area during spring time: results from KORUSAQ. Atmos Chem Phys 18:7149-7168. https://doi.org/10.5194/acp-18-7149-2018

Kim JM, Chung YS, Jo HJ, Lee NJ, Kim MS, Woo SH, Park S, Kim JW, Kim HM, Han MG (2020) Identification of coronavirus isolated from a patient in Korea with COVID-19. Osong public health and research perspectives 11(1):3-7. https://doi.org/10.24171/j.phrp.2020.11.1.02

Knight V (1980) Viruses as agents of airborne contagion. Ann N Y Acad Sci 353:147-156. https://doi.org/10. 1111/j.1749-6632.1980.tb18917.x

Jaenicke R (1982) Physical aspects of the atmospheric aerosol. In: Georgii HW, Jaeschke W (eds) Chemistry of the unpolluted and polluted troposphere. NATO advanced study institutes series (Series C - Mathematical and Physical Sciences), vol 96. Springer, Dordrecht. https://doi.org/10.1007/978-94-009-7918-5_14

Jennings SG (1988) The mean free path in air. J Aerosol Sci 19(2):159-166, ISSN 0021-8502. https://doi.org/10. $1016 / 0021-8502(88) 90219-4$

Lakdawala S, Gaglia M (2020) What we do and do not know about COVID-19's infectious dose and viral load, The Conversation, April 18, 2020, https://theconversation.com/what-we-do-and-do-not-know-about-covid19s-infectious-dose-and-viral-load-135991

La Rosa G, Fratini M, Della Libera S, Iaconelli M, Muscillo M (2013) Viral infections acquired indoors through airborne, droplet or contact transmission. Ann Ist Super Sanità 49(2):124-132. https://doi.org/10.4415/ ANN_13_02_03

Leung JM, Yang CX, Tam A, Shaipanich T, Hackett TL, Singhera GK, Dorscheid DR, Sin DD (2020) ACE-2 expression in the small airway epithelia of smokers and COPD patients: implications for COVID-19. Eur Respir J 55(5):2000688

Li T, Zhang Y, Wang J, Xu D, Yin Z, Chen H, Lv Y, Luo J, Zeng Y, Liu Y, Kinney PL, Shi X (2018) All-cause mortality risk associated with long-term exposure to ambient PM2.5 in China: a cohort study. Lancet Public Health 3(10):e470-e477

Lindsley WG, Blanchere FM, Thewlis RE, Vishnu A, Davis KA, Cao G, Palmer JE, Clark KE, Fisher MA, Khakoo R, Beezhold DH (2010) Measurements of airborne influenza virus in aerosol particles from human coughs. PLoS One 5:e15100

Lindsley WG, Pearce TA, Hudnall JB, Davis KA, Davis SM, Fisher MA, Khakoo R, Palmer JE, Clark KE, Celik I, Coffey CC, Blachere FM, Beezhold DH (2012) Quantity and size distribution of cough-generated aerosol particles produced by influenza patients during and after illness. J Occup Environ Hyg 9:443-449

Liu D, Allan J, Whitehead J, Young D, Flynn M, Coe H, McFiggans G, Fleming ZL, Bandy B (2013) Ambient black carbon particle hygroscopic properties controlled by mixing state and composition. Atmos Chem Phys 13:2015-2029. https://doi.org/10.5194/acp-13-2015-2013

Liu Y, Ning Z, Chen Y (2020) Aerodynamic analysis of SARS-CoV-2 in two Wuhan hospitals. Nature. 582:557-560

Lolli S, Chen Y-C, Wang S-H, Vivone G (2020) Impact of meteorology and air pollution on Covid-19 pandemic transmission in Lombardy region, Northern Italy. Sci Rep. 10:16213. https://oi.org/10.21203/rs.3.rs-39280/v1

Losacco C, Perillo A (2018) Particulate matter air pollution and respiratory impact on humans and animals. Environ Sci Pollut Res Int 25(34):33901-33910

Malterud K, Siersma VD, Guassora AD (2016 Nov) Sample size in qualitative interview studies: Guided by information power. Qual Health Res 26(13):1753-1760. https://doi.org/10.1177/1049732315617444

Marais EA, Jacob DJ, Jimenez JL, Campuzano-Jost P, Day DA, Hu W, Krechmer J, Zhu L, Kim PS, Miller CC, Fisher JA, Travis K, Yu K, Hanisco TF, Wolfe GM, Arkinson HL, Pye HOT, Froyd KD, Liao J, McNeill VF (2016) Aqueous-phase mechanism for secondary organic aerosol formation from isoprene: application to the southeast United States and co-benefit of $\mathrm{SO}_{2}$ emission controls. Atmos Chem Phys. 16:1603-1618. https://doi.org/10.5194/acp-16-1603-2016

Massey D, Masih J, Kulshrestha A, Habil M, Taneja A (2009) Indoor/outdoor relationship of fine particles less than $2.5 \mu \mathrm{m}(\mathrm{PM} 2.5)$ in residential homes locations in central Indian region. Build Environ 44(10):2037-2045

Mohammed MOA, Song W-W, Ma W-L, Li W-L, Ambuchi JJ, Thabit M, Li Y-F (2015) Trends in indooroutdoor PM2.5 research: a systematic review of studies conducted during the last decade (2003-2013). Atmospheric Pollution Research 6(5):893-903

Morawska L, Cao J (2020) Airborne transmission of SARS-CoV-2: the world should face the reality. Environ Int 139:105730. https://doi.org/10.1016/j.envint.2020.105730

Morawska L, Johnson G, Ristovski Z, Hargreaves M, Mengersen KL et al (2009) Size distribution and sites of origin of droplets expelled during expiratory activities. J Aerosol Sci 40(3):256-269

Morris JW (2002)Chemical kinetics and microphysics of atmospheric aerosols, doctoral thesis 
Nicas M, Nazaroff WW, Hubbard A (2005) Toward understanding the risk of secondary airborne infection: emission of respirable pathogens. J Occup Environ Hyg 2(3):143-154. https://doi.org/10.1080/ 15459620590918466

Nikitin N, Petrova E, Trifonova E, Karpova O (2014) Influenza virus aerosols in the air and their infectiousness. Hindawi Publishing Corporation Advances in Virology, p 859090, 6 pages. https://doi.org/10.1155/2014/859090

Pallarés S, Trinidad Gómez E, Martínez A, Jordán MM (2019) The relationship between indoor and outdoor levels of PM10 and its chemical composition at schools in a coastal region in Spain. Heliyon 5(8):e02270

Palmer PI, Jacob DJ, Fiore AM, Martin RV, Chance K, Kurosu TP (2003) Mapping isoprene emissions over North America using formaldehyde column observations from space. J Geophys Res-Atmos. 108:4180. https://doi.org/10.1029/2002JD002153

Pan Y, Zang D, Yang P, Poon LM, Wang Q (2020) Viral load of SARS-CoV-2 in clinical samples. Lancet 20: $411-412$

Pandolfi M, Gonzalez-Castanedo Y, Alastuey A, de la Rosa J, Mantilla E, Sanchez de la Campa A, Querol X, Pey J, Amato F, Moreno T (2011) Source apportionment of PM10 and PM2.5 at multiple sites in the strait of Gibraltar by PMF: impact of shipping emissions. Environ Sci Pollut Res 18:260-269

Papineni RS, Rosenthal FS (1997) The size distribution of droplets in the exhaled breath of healthy human subjects. J Aerosol Med 10(2):105-116

Park M, Joo HS, Lee K, Jang M, Kim SD, Kim I, Borlaza LJS, Lim H, Shin H, Chung KH, Choi YH, Park SG, Bae MS, Lee J, Song H, Park K (2018) Differential toxicities of fine particulate matters from various sources. Sci Rep 8:17007. https://doi.org/10.1038/s41598-018-35398-0

Pfefferle S, Huang J, Nörz D, Indenbirken D, Lütgehetmann M, Oestereich L, Günther T, Grundhoff A, Aepfelbacher M, Fischer N (2020) Complete genome sequence of a SARS-CoV-2 strain isolated in Northern Germany. Microbiol Resour Announc 9(23):e00520-e00520. https://doi.org/10.1128/MRA.00520-20

Phan-Cong L, Dinh-Van P (1973) Direct measurements of coalescence efficiency and frequency of small water droplets in an electric field. Tellus 25(1):63-68. https://doi.org/10.3402/tellusa.v25i1.9645

Pilz LR et al (2012) Statistical considerations and endpoints for clinical lung cancer studies: Can progression free survival (PFS) substitute overall survival (OS) as a valid endpoint in clinical trials for advanced non-smallcell lung cancer? Transl Lung Cancer R 1(1):26-35. https://doi.org/10.3978/j.issn.2218-6751.2011.12.08

Pope CA, Thun MJ, Namboodiri MM, Dockery DW, Evans JS, Speizer FE, Heath CW (1995) Particulate air pollution as a predictor of mortality in a prospective study of U.S. adults. Am J Respir Crit Care Med 151: 669-674

Pruppacher HR, Klett JD (1997) Microphysics of clouds and precipitation, 2nd edition, vol 954. Kluwer Academic Publishers, Dordrecht, p 954

Riediker M, Tsai D (2020) Estimation of viral aerosol emissions from simulated individuals with asymptomatic to moderate coronavirus disease 2019. JAMA Netw Open 3(7):e2013807. https://doi.org/10.1001/ jamanetworkopen.2020.13807

Rothe C, Schunk M, Sothmann P, Bretzel G, Froeschl G, Wallrauch C, Zimmer T, Thiel V, Janke C, Guggemos W, Seilmaier M, Drosten C, Vollmar P, Zwirglmaier K, Zange S, Wölfel R, Hoelscher M (2020) Transmission of 2019-ncov infection from an asymptomatic contact in Germany. N Engl J Med 382(10): 970-971. https://doi.org/10.1056/NEJMc2001468

Russell A, Milford J, Bergin M, McBride S, McNair L, Yang Y, Stockwell W, Croes B (1995) Urban ozone control and atmospheric reactivity of organic gases. Science 269:491-495. https://doi.org/10.1126/science. 269.5223.491

Samara C, Kouimtzis T, Tsitouridou R, Kanias G, Simeonov V (2003) Chemical mass balance source apportionment of PM10 in an industrialized urban area of Northern Greece. Atmos Environ 37:41-54

Sandelowski M (1995) Sample size in qualitative research. Res Nurs Health 18:179-183. https://doi.org/10.1002/ nur.4770180211

Saramak A (2019) Comparative analysis of indoor and outdoor concentration of PM10 particulate matter on example of Cracow City Center. Int J Environ Sci Technol 16:6609-6616. https://oi.org/10.1007/s13762-019-02250-5

Santarpia JL, Rivera DN, Herrera V (2020) Aerosol and surface transmission potential of SARS-CoV-2. medRxiv 2020.03.23.20039446 published online June 3

Sattar SA, Ijaz MK (1987) Spread of viral infections by aerosols. Crit Rev Environ Control 17(2):89-131. https:// doi.org/10.1080/10643388709388331

Scott GH, Sydiskis RJ (1976) Responses of mice immunized with influenza virus by aerosol and parenteral routes. Infect Immunity 13:696-703

Seinfeld JH, Pandis SN (1998) Atmospheric chemistry and physics: from air pollution to climate change. Wiley, NY, USA, pp 408-442

Setti L, Passarini F, De Gennaro G, Barbieri P, Perrone MG, Piazzalunga AA, Borelli M, Palmisani J, Di Gilio A, Piscitelli P, Miani A (2020a) The potential role of particulate matter in the spreading of COVID-19 in Northern Italy: first evidence-based research hypotheses, accepted for publication. In: BMJ Open 
Setti L, Passarini F, De Gennaro G, Barbieri P, Perrone MG, Borelli M, Palmisani J, Di Gilio A, Torboli V, Pallavicini A, Ruscio M, Piscitelli P, Miani A (2020b) SARS-Cov-2 RNA found on particulate matter of Bergamo in Northern Italy: first preliminary evidence. Environ Res. https://doi.org/10.1016/j.envres.2020.109754

Setti L, Passarini F, De Gennaro G, Barbieri P, Pallavicini A, Ruscio M, Piscitelli P, Colao A, Miani A (2020c) Searching for SARS-COV-2 on particulate matter: a possible early indicator of COVID-19 epidemic recurrence. Int J Environ Res Public Health 17:2986

Shields L, Twycross A (2003) The difference between incidence and prevalence. Nursing Children and Young People 15(7):50-50. https://doi.org/10.7748/paed.15.7.50.s31

Smoluchowski M (1916) Zusammenfassende Bearbeitungen. Drei Vorträge über Diffusion, Brownsche Molekularbewegung und Koagulation von Kolloidteilchen. Phys Z 17:557

Smoluchowski M (1918) Versuch einer mathematischen Theorie der Koagulationskinetik kolloiderLösnngen. A Phys Chem. 92:129

Stumm W (1992) Chemistry of the solid-water interface: interface in natural systems. Wiley, New York

Taiwo AM, Beddows DCS, Shi Z, Harrison RM (2014) Mass and number size distributions of particulate matter components: comparison of an industrial site and an urban background site. Sci Total Environ 475:29-38, ISSN 0048-9697. https://doi.org/10.1016/j.scitotenv.2013.12.076

Tellier R (2009) Aerosol transmission of influenza A virus: a review of new studies. J R Soc Interface 6:S783S790. https://doi.org/10.1098/rsif.2009.0302.focus

Tsuda A, Henry FS, Butler JP (2013) Particle transport and deposition: basic physics of particle kinetics. Comprehensive Physiol 3(4):1437-1471. https://doi.org/10.1002/cphy.c100085

Tyrrell DAJ (1967) The spread of viruses of the respiratory tract by the airborne route. Symp Soc Gen Microbiol 17:286-306

van Doremalen et al (2020) Aerosol and surface stability of SARS-CoV-2 as compared with SARS-CoV-1. N Engl J Med 382:1564-1567. https://doi.org/10.1056/NEJMc2004973

Vecchi R, Marcazzan GM, Valli G (2005) Seasonal variation of 210Pb activity concentration in outdoor air of Milan (Italy). J Environ Radioact 82:251-286

Vecchi R, Marcazzan G, Valli G (2007) A study on nighttime-daytime PM10 concentration and elemental composition in relation to atmospheric dispersion in the urban area of Milan (Italy). Atmospheric Environ 41:2136-2144

Verrilli S et al. (2010) PM2.5 size distribution and characterization by carbon isotope in Tuscany (Italy), Advanced Atmospheric Aerosol Symposium, 19-22 September 2010 Florence, Italy

Xie X, Li Y, Chwang AT, Ho PL, Seto WH (2007) How far droplets can move in indoor environments-revisiting the Wells evaporation-falling curve. Indoor Air 17:211-225

Yezli S, Otter JA (2011) Minimum infective dose of the major human respiratory and enteric viruses transmitted through food and the environment. Food and Environmental Virology 3(1):1-30. https://doi.org/10.1007/ s12560-011-9056-7

Wan GH, Wu CL, Chen YF, Huang SH, Wang YL, Chen CW (2014) Particle size concentration distribution and influences on exhaled breath particles in mechanically ventilated patients. PLoS One 9(1):e87088. https:// doi.org/10.1371/journal.pone.0087088

Watanabe T, Bartrand TA, Weir MH, Omura T, Haas CN (2010) Development of a dose-response model for SARS coronavirus risk analysis. (30)7:1129-1138, https://doi.org/10.1111/j.1539-6924.2010.01427.x

WHO (2005)Air quality guidelines for particulate matter, ozone, nitrogen dioxide and sulfur dioxide. Global update 2005, https://apps.who.int/iris/bitstream/handle/10665/69477/WHO_SDE_PHE_OEH_06.02_eng. pdf? sequence $=1$. Last Accessed July $12^{\text {th }}, 2020$

WHO (2020a) Modes of transmission of virus causing COVID-19: implications for infection prevention and control (IPC) precaution recommendations, Scientific Brief, WHO reference number: WHO/2019-nCoV/ Sci_Brief/Transmission_modes/2020.2. https://www.who.int/news-room/commentaries/detail/modes-oftransmission-of-virus-causing-covid-19-implications-for-ipc-precaution-recommendations

WHO (2020b) Transmission of SARS-CoV-2: implications for infection prevention precautions, Scientific Brief, WHO reference number: WHO/2019-nCoV/Sci_Brief/Transmission_modes/2020.3. https://www.who.int/ publications/i/item/modes-of-transmission-of-virus-causing-covid-19-implications-for-ipc-precautionrecommendations

Wölfel R, Corman VM, Guggemos W, Seilmaier M, Zange S, Müller MA, Niemeyer D, Jones TC, Vollmar P, Rothe $C$ et al (2020) Virological assessment of hospitalized patients with COVID-2019. Nature 581:465-469

Yang W, Li J, Wang M, Sun Y, Wang Z (2018) A case study of investigating secondary organic aerosol formation pathways in Beijing using an observation-based SOA box model. Aerosol Air Qual Res 18:16061616. https://doi.org/10.4209/aaqr.2017.10.0415 